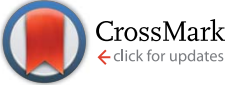

Cite this: RSC Adv., 2016, 6, 68028

Received 28th April 2016

Accepted 8th July 2016

DOI: 10.1039/c6ra11021e

www.rsc.org/advances

\section{Substitution driven structural and magnetic properties and evidence of spin phonon coupling in $\mathrm{Sr}$-doped $\mathrm{BiFeO}_{3}$ nanoparticles $\uparrow$}

\begin{abstract}
Sunil Chauhan, ${ }^{a}$ Manoj Kumar*a and Prabir Pal ${ }^{\mathrm{b}}$
The manifestation of dimensionalities and $\mathrm{Sr}$ induced modifications in structural, vibrational and magnetic properties of $\mathrm{Bi}_{1-x} \mathrm{Sr}_{x} \mathrm{FeO}_{3} ;(x=0-0.25)$ nanoparticles synthesized by a tartaric acid based sol-gel route are reported. X-ray diffraction and electron microscopy studies reveal the phase purity and nanocrystalline nature (45-90 nm) of $\mathrm{Bi}_{1-x} \mathrm{Sr}_{x} \mathrm{FeO}_{3}$ samples. The $\mathrm{Sr}$ ions substitution motivated the coexistance of rhombohedral $(R 3 C)$ and pseudo tetragonal $(P 4 / \mathrm{mmm})$ structural symmetry for the $x=0.25$ sample which leads to enhancement of saturation magnetization due to the distorted cycloid spin structure and uncompensated surface spins, which is in concomitance with the electron paramagnetic resonance (EPR) and Mössbauer studies. The ferromagnetic ordering contribution continuously increases with increasing Sr content from $x=0-0.25$ samples with a maximum saturation magnetization of $0.72 \mathrm{emu}$ $\mathrm{g}^{-1}$ for the $x=0.25$ sample which is also endorsed by second order Raman modes. X-ray photoelectron and Mössbauer measurements confirmed the dominance of the $\mathrm{Fe}^{3+}$ oxidation state. Alteration in QS hyperfine parameters and line-width analysis have been probed by Mössbauer analysis with increasing $\mathrm{Sr}$ content in $\mathrm{BiFeO}_{3}$ nanoparticles suggesting the destruction of the spin cycloid.
\end{abstract}

\section{Introduction}

Over the past few years, multiferroics have captured great attention for their potential application in the emerging field of multifunctional devices. Multiferroics simultaneously possess ferroic properties, such as ferroelectricity, ferromagnetism and ferroelasticity, coupled with electric, magnetic and structural order parameters. ${ }^{1-4}$ So far, several single-phase multiferroics have been developed such as $\mathrm{DyMnO}_{3}, \mathrm{BiMnO}_{3}, \mathrm{YMnO}_{3}$ and $\mathrm{BiFeO}_{3} \cdot{ }^{4}$ Among these multiferroics, $\mathrm{BiFeO}_{3}$ is known to be the only room temperature multiferroic, which is a potential candidate for several applications in different fields such as electromagnetic wave attenuation, resistive switching, gas sensors, solar cells, oxygen photocatalytic and simultaneous multi-harmonic imaging of nanoparticles in tissues. ${ }^{-9} \mathrm{BiFeO}_{3}$ shows ferroelectricity $\left(T_{\mathrm{C}}=\right.$ $\left.826-845{ }^{\circ} \mathrm{C}\right)$ and antiferromagnetism $\left(T_{\mathrm{N}}=370{ }^{\circ} \mathrm{C}\right)$ in single phase at room temperature and has rhombohedrally distorted perovskite structure with space group $R 3 c$, having rhombohedral lattice parameters $a_{\mathrm{r}}=5.63 \AA, \alpha_{\mathrm{r}}=59.35^{\circ}$, or alternatively, hexagonal parameters $a_{\text {hex }}=5.58 \AA, c_{\text {hex }}=13.87 \AA .{ }^{4,5}$ In $\mathrm{BiFeO}_{3}$,

${ }^{a}$ Department of Physics and Materials Science \& Engineering, Jaypee Institute of Information Technology, A-10, Sector-62, Noida-201307, India. E-mail: mkumar. phy@gmail.com

${ }^{b}$ Academy of Scientific and Innovative Research (AcSIR), CSIR-National Physical Laboratory (CSIR-NPL) Campus, Dr K S Krishnan Road, New Delhi 110012, India

$\uparrow$ Electronic supplementary information (ESI) available. See DOI: 10.1039/c6ra11021e ferroelectricity arises due to stereochemically active $6 s^{2}$ lone pair electrons of $\mathrm{Bi}^{3+}$ ions and it is displacive-type ferroelectric material. ${ }^{3,4}$ In displacive-type ferroelectric materials, the most fundamental requirement is atomic displacement along the specific direction in their crystal structure to induce a spontaneous polarization. $\mathrm{Bi}^{3+}$ and $\mathrm{Fe}^{3+}$ cations are displaced along the hexagonal [001]-axis, leading to a spontaneous polarization in this direction. At the same time, magnetic moments of $\mathrm{Fe}^{3+}$ cations exhibit a canted antiferromagnetic G-type ordering with a small canting angle. The residual net magnetic moment of the canted antiferromagnetic state is canceled by a long-range modulated spin structure with a period length of about $62 \mathrm{~nm}$. This longrange modulation can be modeled by cycloidal structure of $\mathrm{Fe}^{3+}$ magnetic moments with $[110]_{\text {hex }}$ as propagation vector and magnetic moments pointing in the plane defined by the cycloidal propagation and the polarization vector., ${ }^{3,4}$ However, weak magnetic behavior and leakage currents in $\mathrm{BiFeO}_{3}$ are main drawbacks for its applications. ${ }^{4,5}$ Many current investigations seek to suppress the spiral spin structure in $\mathrm{BiFeO}_{3}$ to enhance the magnetic properties and consequently to enhance the multiferroic properties. It is widely expected that the strategies based on decreasing the particle size (nanomaterials), divalent cations (Ba, $\mathrm{Ca}, \mathrm{Sr}$ and $\mathrm{Pb}$ ), transition metal ions ( $\mathrm{Ti}, \mathrm{Nb}, \mathrm{W}, \mathrm{Co}, \mathrm{Mn}$ and $\mathrm{Ni}$ ) and rare-earth metal ions Lanthanide series $(\mathrm{R}=\mathrm{Dy}, \mathrm{Gd}, \mathrm{Eu}$ and Pr) substitution will have great impact on their magnetic, electric, optical and magnetoelectric properties. ${ }^{\mathbf{1 0 - 1 7}}$ Rare earth ions are magnetically active ions leading to the orthoferrites $\left(\mathrm{RFeO}_{3}\right)$ orthorhombic phase (ferromagnetic). It is difficult to measure the 
solubility limit and phase identification of the rare earth ions doped $\mathrm{BiFeO}_{3}$ ceramics as discussed by D. C. Arnold. ${ }^{15}$ Transition metal ions $\left(\mathrm{Ti}^{4+}, \mathrm{Nb}^{5+}\right.$ and $\mathrm{W}^{6+}$ ) doped $\mathrm{BiFeO}_{3}$ ceramics form the core@shell $\mathrm{BiFeO}_{3} @ \mathrm{Bi}_{3-\delta} \mathrm{Fe}_{5} \mathrm{O}_{12}$ type microstructure and the impurity phase increases with increasing the transition metal aliovalancy. ${ }^{14}$ Recently, significant efforts have been made to understand the effect of chemical substitution of $\mathrm{Sr}$ on the crystal structure and magnetic properties of $\mathrm{BiFeO}_{3}$ ceramics. ${ }^{18-24}$ The ionic radius of $\mathrm{Sr}^{2+}$ ion (1.26 $\left.\mathrm{\AA}, \mathrm{CN} 8\right)$ is slightly larger than that of $\mathrm{Bi}^{3+}$ ion (1.17 $\left.\mathrm{A}, \mathrm{CN} 8\right)$, which can lead to the lattice distortion in $\mathrm{BiFeO}_{3}$ crystal. The $\mathrm{Sr}^{2+}$ ion is magnetically inactive and the distortion due to the ionic radii difference in crystal structure is expected to enhance the magnetization in $\mathrm{BiFeO}_{3}$ even for small doping concentration. These changes affect the degree of offcentering of the $\mathrm{FeO}_{6}$ octahedra and thus, also the multiferroic properties of $\mathrm{BiFeO}_{3}$. Charge compensation for the substitution of $\mathrm{Sr}^{2+}$ for $\mathrm{Bi}^{3+}$ in $\mathrm{BiFeO}_{3}$ ceramics could occur by the introduction of vacancies on oxygen sites or by oxidation of $\mathrm{Fe}^{3+}$ to $\mathrm{Fe}^{4+}$ giving solid solutions between $\mathrm{BiFeO}_{3}$ and $\mathrm{SrFe}^{3+} \mathrm{O}_{2.5}$ or $\mathrm{SrFe}^{4+} \mathrm{O}_{3}$, respectively. Hussain et al. reported the pseudo cubic crystal structure and $\mathrm{Fe}$ ions are in trivalent state along with the oxygen deficiency in $25 \% \mathrm{Sr}$ doped $\mathrm{BiFeO}_{3}$ ceramics using the X-ray diffraction and Mössbauer spectroscopy results. ${ }^{19}$ Bhushan et al. showed the rhombohedral structure with dominancy of $\mathrm{Fe}^{3+}$ ions in $0-7 \% \mathrm{Sr}$ doped $\mathrm{BiFeO}_{3}$ nanoparticles. ${ }^{20}$ Kundys et al. reported the magnetic field induced polarization of $P_{\mathrm{r}}=96 \mu \mathrm{C} \mathrm{cm}^{-2}$ at $10 \mathrm{~T}$ in $\mathrm{Bi}_{0.75} \mathrm{Sr}_{0.25} \mathrm{FeO}_{3-\delta}$ ceramic is highest among the experimentally reported value for all previously reported $\mathrm{BiFeO}_{3}$ based systems among thin films or bulk samples. ${ }^{21}$ However there are several contradictory reports available on crystal structure and magnetic properties of $\mathrm{Sr}$ doped $\mathrm{BiFeO}_{3}$ ceramics with respect to the role of the Fe oxidation state $\left(\mathrm{Fe}^{2+}, \mathrm{Fe}^{3+}\right.$ and $\left.\mathrm{Fe}^{4+}\right)$ or/and coordination and crystal structures. ${ }^{21-23}$ The structural, magnetic and ferroelectric properties of $50 \% \mathrm{Sr}$ doped $\mathrm{BiFeO}_{3}$ with rhombohedral crystal structure and Fe ions with +2 and +3 oxidation states have been reported by Balamurugan et al. ${ }^{22}$ Contrarily, Li et al. found that Fe ions maintained $\mathrm{a}+3$ state and the magnetization of the samples decreases with increasing $\mathrm{Sr}$ content which they attributed to the decrease in coordination of $\mathrm{Fe}^{3+}$ from octahedral to tetrahedral. ${ }^{23}$ Mandal et al. with XPS analysis showed that Fe ions exhibited $\mathrm{Fe}^{3+}$ and $\mathrm{Fe}^{4+}$ state along with the presence of oxygen vacancies. $^{24}$ Furthermore, the increasing amount of oxygen vacancy would result in another interesting electrical conductive phenomenon e.g., threshold switching (TS) effect which can be used in electronic devices. ${ }^{25}$ Among the various reasons of incompleteness on the studies of $\mathrm{Bi}_{1-x} \mathrm{Sr}_{x} \mathrm{FeO}_{3}$ system includes the different values of $x$. The other reasons (like dependence of sample properties) strongly depend on method of preparation (i.e. solid state or sol-gel route) and processing conditions. ${ }^{18-24}$

Previous structural and Mössbauer studies were carried out mostly on bulk-Sr doped $\mathrm{BiFeO}_{3}$ samples to ravel structural transformation and its long-range ordering but few reports were available on $\mathrm{Sr}$ doped $\mathrm{BiFeO}_{3}$ nanoparticles. SQUID (or VSM) magnetic measurements provided information on net magnetization, but no further insight into the spin structure of nanoparticles using Electron Paramagnetic Resonance studies were done. In this Communication, we present the detailed study of structural and magnetic properties of $\mathrm{Bi}_{1-x} \mathrm{Sr}_{x} \mathrm{FeO}_{3}$ nanoparticles $(x=0,0.05,0.1,0.15,0.20$ and 0.25$)$. Nano-crystalline samples are prepared by modified sol-gel route and systematically investigated for changes in the crystallographic structure, microstructure and magnetic properties by using Rietveld analysis, TEM, Raman, XPS, VSM, EPR and Mössbauer techniques. The origin of the mixed rhombohedral and pseudo tetragonal structural state is elaborated with substitution induced lattice and octahedral distortions in a perovskite unit cell and the structural changes are correlated with magnetic properties. X-ray Photoelectron Spectroscopy (XPS) results confirmed the $\mathrm{Fe}^{3+}$ dominancy in $\mathrm{Sr}$ doped $\mathrm{BiFeO}_{3}$ nanoparticles. Mössbauer spectroscopy results showed the distorted cycloidal spin structure in $\mathrm{Sr}$ doped $\mathrm{BiFeO}_{3}$ nanoparticles.

\section{Experimental details}

\subsection{Materials synthesis}

Pure and $\mathrm{Sr}$ doped $\mathrm{BiFeO}_{3}$ nanoparticles were prepared by tartaric acid modified sol-gel route. All chemical (Sigma) reagents used as starting materials were analytic grade and do not require additional purification treatment. In a typical sol-gel process for $\mathrm{BiFeO}_{3}$ nanoparticles, calculated amounts of bismuth nitrate $\left(\mathrm{Bi}\left(\mathrm{NO}_{3}\right)_{3} \cdot 5 \mathrm{H}_{2} \mathrm{O}\right)$ and ferric nitrate $\left(\mathrm{Fe}\left(\mathrm{NO}_{3}\right)_{3}\right.$ $\left.\cdot 9 \mathrm{H}_{2} \mathrm{O}\right)$ were dissolved in deionized water. $\mathrm{As} \mathrm{Bi}\left(\mathrm{NO}_{3}\right)_{3} \cdot 5 \mathrm{H}_{2} \mathrm{O}$ undergoes decomposition into bismuth oxychloride in water, it was first taken in $50 \mathrm{ml}$ deionized water and kept on stirring. During stirring dilute nitric acid was added drop by drop until a clear and transparent solution was obtained which confirmed the complete dissolution of $\mathrm{Bi}\left(\mathrm{NO}_{3}\right)_{3} \cdot 5 \mathrm{H}_{2} \mathrm{O}$ and then ferric nitrate solution was added. The stoichiometric amount of tartaric acid $\left(\mathrm{C}_{6} \mathrm{H}_{6} \mathrm{O}_{7}\right)$ was further added for complete combustion of the nitrates. In present report tartaric acid was used as chelating agent for the synthesis of $\mathrm{Sr}$ doped $\mathrm{BiFeO}_{3}$ nanoparticles. It is difficult to obtain phase pure $\mathrm{BiFeO}_{3}$ samples and several secondary phases $\left(\mathrm{Bi}_{2} \mathrm{O}_{3}, \mathrm{Bi}_{2} \mathrm{Fe}_{4} \mathrm{O}_{9}\right.$ and $\left.\mathrm{Bi}_{46} \mathrm{Fe}_{2} \mathrm{O}_{72}\right)$ exist in the samples synthesized with citric acid as chelating agent. $\mathrm{S}$. Gosh et al. and M. Arora et al. reported pure phase formation of $\mathrm{BiFeO}_{3}$ nanoparticles by using tartaric acid as chelating agent. ${ }^{26}$ The uniqueness of the tartaric acid as a chelating agent in synthesis of $\mathrm{BiFeO}_{3}$ nanoparticles probably resides in the formation of hetero-metallic polynuclear complexes in the solution, where reacting metal atoms come in close proximity. This occurs because of the presence of two carboxylate and two hydroxyl groups with proper orientation to form a polynuclear complex, which breaks on heating in the presence of concentrated $\mathrm{HNO}_{3}$ leading to the formation of pure phase $\mathrm{BiFeO}_{3}$ samples. The yellow transparent solution was stirred vigorously for $12 \mathrm{~h}$ at $60^{\circ} \mathrm{C}$. Further the transparent solution was dried for two days in an oven maintained at $120{ }^{\circ} \mathrm{C}$ to get the fluffy gel. Finally, the fluffy gel was calcined at different temperatures 400 , 500 and $600{ }^{\circ} \mathrm{C}$ for two hrs in an air ambience. Sr doped $\mathrm{BiFeO}_{3}$ samples with different $\mathrm{Sr}$ doping concentrations were prepared by adding the calculated amount $\mathrm{Sr}\left(\mathrm{NO}_{3}\right)_{2} \cdot 5 \mathrm{H}_{2} \mathrm{O}$ in the precursor solution keeping all other experimental conditions invariant. 


\subsection{Characterization}

The prepared samples were structurally characterized by X-Ray diffractometer (XRD-6000 Shimadzu). The measurements were carried out at room temperature using $\mathrm{Cu} \mathrm{K}_{\alpha}$ radiation source $(\lambda$ $=1.5406 \AA$, operated at $40 \mathrm{kV}$ and $30 \mathrm{~mA}$ ) and the data was collected in the range $2 \theta=10^{\circ}$ to $95^{\circ}$ with the step size of $0.02^{\circ}$ and 1.2 seconds count time at each step. Rietveld refinement analysis of the XRD patterns were performed with Program FullProf (Version 3.00-June 2015). Si sample has been used as an external standard to deconvolute the contribution of instrumental broadening. The instrumental parameters were kept constant during the fitting. Program refinement of the first sample was started with the space group $R 3 c$ with $\mathrm{O}$ at $18 \mathrm{~b}$-site, $\mathrm{Bi}$ at $6 \mathrm{a}$-site and $\mathrm{Fe}$ at $6 \mathrm{a}$-site and the global parameters were refined in the first step. In the next step, the structural parameters such as lattice parameter, atomic coordinates and site occupancy were refined. The fitting quality of the experimental data was checked by using the goodness of fitting parameter $\left(\chi^{2}\right)$. Scanning electron microscopic images were recorded by using a Zeiss Ultra Plus field-emission scanning electron microscope (FESEM) operated at $10 \mathrm{kV}$. The TECNAI with $\mathrm{LaB}_{6}$ electron source was used for High Resolution Transmission Electron Microscope (HRTEM) operated at $200 \mathrm{kV}$ to image pure and $\mathrm{Sr}$ doped $\mathrm{BiFeO}_{3}$ nanoparticles. The samples for the TEM analysis were prepared by placing a drop of dilute suspension of nanoparticles on carbon coated copper grid. Raman spectroscopy was carried out in the backscattering configuration (LabRAM HR) with charge coupled device detector and 514.5 and $785 \mathrm{~nm}$ laser excitation sources. The laser power was kept below $2 \mathrm{~mW}$ in order to avoid any sample heating. The X-ray photoelectron spectroscopy (XPS) measurements were performed by using an Omicron $\mu$-metal ultrahigh vacuum (UHV) system equipped with a monochromatic $\mathrm{Al} \mathrm{K}_{\alpha} \mathrm{X}$-ray source $(h v=1486.6$ eV) and a multi-channeltron hemispherical electron energy analyzer (EA 125). The C 1s core levels were measured throughout the experiment particularly before and after each XPS spectra. The samples were heated in situ at $300{ }^{\circ} \mathrm{C}$ under ultra high vacuum conditions and then cooled down to room temperature before photoemission measurements. This heating procedure helped us to clean the sample surface. The photoemission measurements were performed in the analysis chamber under a base vacuum of $\sim 5.0 \times 10^{-11}$ mbar at room temperature. The room temperature magnetic measurements of samples were carried out using vibrating sample magnetometer (Lakeshore VSM 7410). The magnetic resonance spectra were recorded with an electron paramagnetic resonance (EPR) spectrometer (JES FA200 CW ESR Spectrometer) using X-band gun diode. The samples were rolled into cylindrical shapes by wrapping them in Teflon tapes. These samples were stuffed into a quartz capillary tube. The sample was placed at the centre of the resonant cavity between pole caps of an electromagnet. The magnetic field was scanned from 0-800 $\mathrm{mT}$, while the resonance frequency $(\sim 9.46 \mathrm{GHz})$ of the sample cavity was locked. Mössbauer effect measurements were carried out by using a standard PC-based spectrometer equipped with a Weissel velocity drive operating in the constant acceleration mode.

\section{Result and discussion}

\subsection{X-ray diffraction analysis}

Fig. 1(a) illustrates the X-ray diffraction patterns of $\mathrm{BiFeO}_{3}$ samples sintered at 400,500 and $600{ }^{\circ} \mathrm{C}$ respectively. It has been clearly observed that there is no $\mathrm{BiFeO}_{3}$ diffraction peak except amorphous phase $\left(2 \theta \sim 30^{\circ}\right)$ in the sample sintered at $400{ }^{\circ} \mathrm{C}$. With increasing the sintering temperature to $500{ }^{\circ} \mathrm{C}$, the XRD pattern expectedly shows the typical peaks of rhombohedral structure (JCPDS card number 71-2494) indicates the presence of crystalline $\mathrm{BiFeO}_{3}$ ceramics. ${ }^{27,28}$ With further increasing the sintering temperature to $600{ }^{\circ} \mathrm{C}$, the intensities of $\mathrm{BiFeO}_{3}$ diffraction peaks are found to increase suggesting improved nature of crystallization. Fig. 1(b) shows the X-ray diffraction patterns and its magnified view (near $2 \theta \sim 32^{\circ}$ and $39.5^{\circ}$ ) for $\mathrm{Bi}_{1-x} \mathrm{Sr}_{x} \mathrm{FeO}_{3}(x=0-0.25)$ samples sintered at temperature 600 ${ }^{\circ} \mathrm{C}$. Diffraction peaks (104) and (110) are clearly separated for $x$ $=0.0$ sample (pure $\mathrm{BiFeO}_{3}$ ), however, on increasing Sr content from $x=0.05$ to 0.25 , doublet (104) and (110) merged to a single peak. Moreover, (113) and (006) peaks are suppressed with increasing $\mathrm{Sr}$ content. Although ionic size of $\mathrm{Sr}^{2+}(1.26 \AA)$ is greater than $\mathrm{Bi}^{3+}(1.17 \AA)$ and we may expect an increase of the lattice constant and consequent decrease of $2 \theta$ with increasing Sr content, but the converse effect has been observed. All the diffraction peaks shift towards higher angles with increasing $\mathrm{Sr}^{2+}$ content up to $x=0.20$ samples indicating decrease in the unit cell volume. However, for $x=0.25$ sample the diffraction peaks (104) and (110) merge to a single peak indicating the signature of structural phase transformation. Merging, suppression and shifting of XRD peaks indicate that Sr doping in $\mathrm{BiFeO}_{3}$ samples results in compressive lattice distortion which leads to evolution of pseudo-tetragonal $P 4 / \mathrm{mmm}$ phase. For detailed structural analysis, the Rietveld refinement of $\mathrm{Bi}_{1-x} \mathrm{Sr}_{x} \mathrm{FeO}_{3} ;(x=0-0.20)$ samples were carried out by considering the rhombohedrally distorted perovskite structure with $R 3 c$ space group. The Bragg peaks are modeled with ThompsonCox-Hastings pseudo-Voigt function and the background is estimated by linear interpolation between selected background points. The refinement of the structural parameters is continued till convergence is reached with goodness of fit (GoF) around 1.0. ${ }^{29}$ Refinement of $\mathrm{Bi}_{0.75} \mathrm{Sr}_{0.25} \mathrm{FeO}_{3}$ sample was performed using the same $R 3 c$ structural model. However, the value of the goodness of fitting parameter $\left(\chi^{2}\right)$ was poor and the overall difference between the observed and calculated profiles was rather large. Careful verification of the profile fitting revealed the existence of extra reflections of low intensity corresponding to a pseudo-tetragonal $P 4 / \mathrm{mmm}$ phase which is typical of $\mathrm{SrFeO}_{3}$-type ferrites. ${ }^{30}$ This implies that the diffraction profile of $x=0.25$ sample might be a result of superposition of two phase contributions rhombohedral $R 3 c$ and pseudotetragonal $P 4 / \mathrm{mmm}$. Using a bi-phasic $(R 3 c+P 4 / \mathrm{mmm})$ model, stable refinement $\left(\chi^{2}=1.86\right)$ with the major contribution from the rhombohedral phase $(65.25 \%)$ and minor contribution from the phase with pseudo-tetragonal $P 4 / \mathrm{mmm}$ (34.75\%) symmetry are obtained. The Rietveld refined XRD patterns for selected samples are shown in Fig. 1(c-f). The various parameters for all 

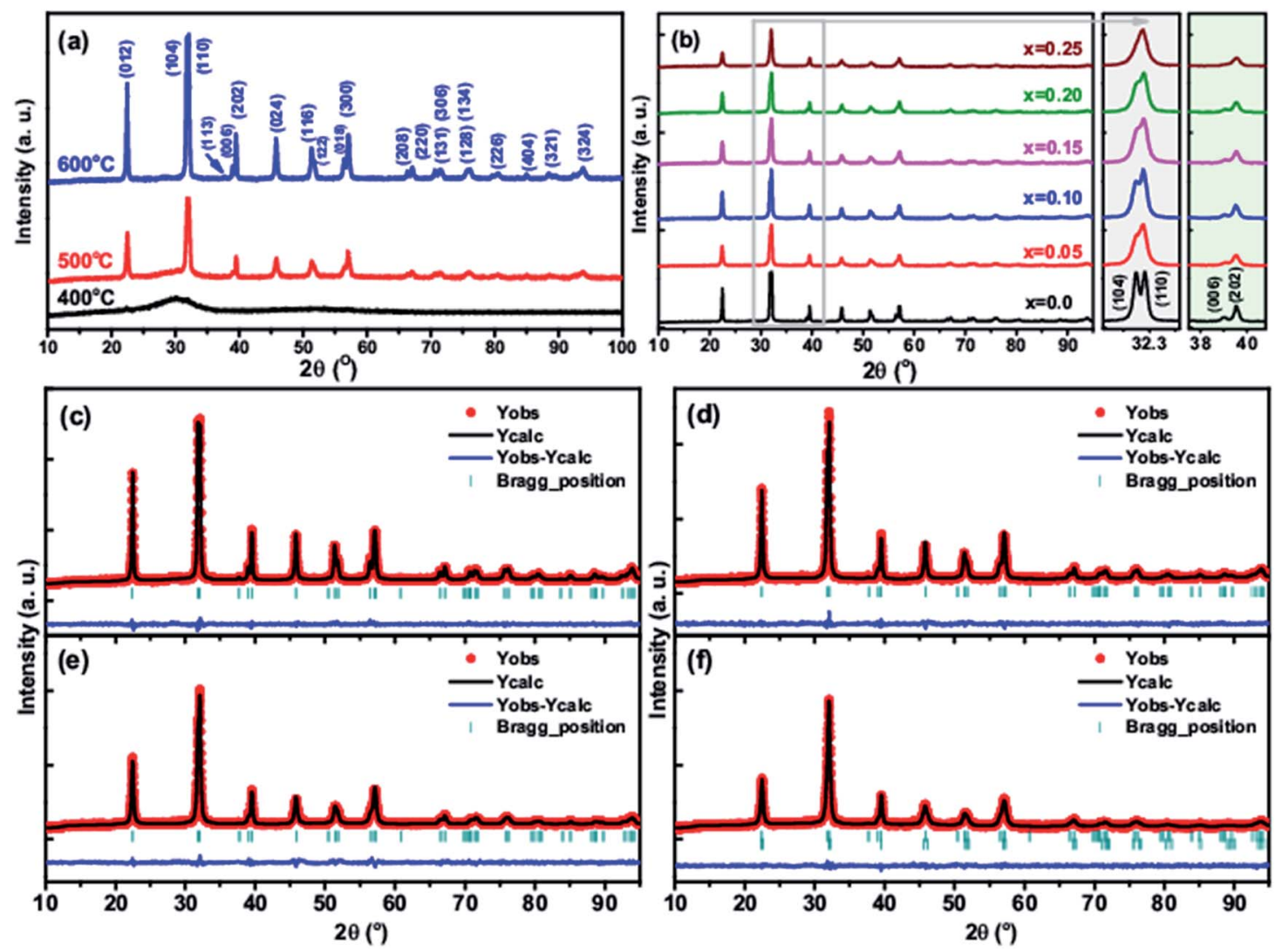

Fig. 1 (a) XRD patterns of $\mathrm{BiFeO}_{3}$ precursor gel sintered at different temperatures. (b) XRD patterns of $\mathrm{Bi}_{1-x} \mathrm{Sr}_{x} \mathrm{FeO}_{3}$ nanoparticles sintered at $600{ }^{\circ} \mathrm{C}$. Rietveld refined XRD patterns of $\mathrm{Bi}_{1-x} \mathrm{Sr}_{x} \mathrm{FeO}_{3}$ nanoparticles, (c) $x=0.0$, (d) $x=0.10$, (e) $x=0.20$ and (f) $x=0.25$.

the samples obtained from refinement of XRD patterns are listed in ESI Table S1. $\dagger$ The crystal structure of pure $\mathrm{BiFeO}_{3}$ (R3c), $\mathrm{Bi}_{0.8} \mathrm{Sr}_{0.2} \mathrm{FeO}_{3}$ (contracted $R 3 c$ ) and $\mathrm{Bi}_{0.75} \mathrm{Sr}_{0.25} \mathrm{FeO}_{3}(R 3 c+$

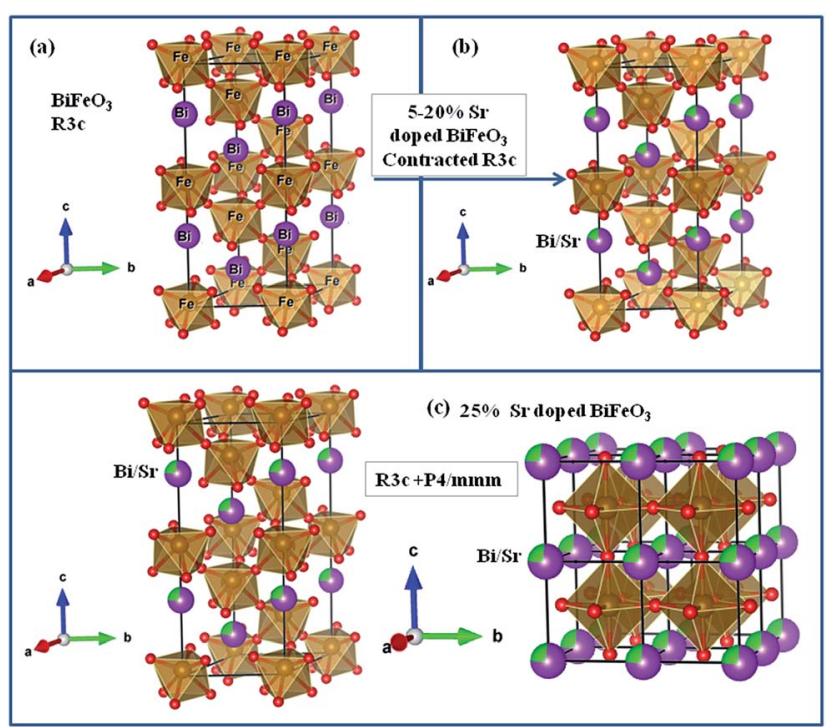

Fig. 2 (a) Rhombohedral perovskite $R 3 c$ structure for pure $\mathrm{BiFeO}_{3}$, (b) contracted rhombohedral perovskite $R 3 c$ structure for $5-20 \% \mathrm{Sr}$ doped $\mathrm{BiFeO}_{3}$ and (c) rhombohedral perovskite $R 3 c+$ pseudo tetragonal $\mathrm{P} 4 / \mathrm{mmm}$ structure for $25 \% \mathrm{Sr}$ doped $\mathrm{BiFeO}_{3}$ (representation is based on the refined ionic positions obtained from Rietveld refinement).
$P 4 / \mathrm{mmm}$ ) generated by refined ionic positions obtained from Rietveld refinement are shown in Fig. $2(\mathrm{a}-\mathrm{c})$. The variation in the lattice constants " $a$ " and " $c$ " and cell volume " $V$ " as a function of Sr content $x$ are given in Table S1. $\dagger$ The unexpected decrease in the lattice constant with increasing Sr content is most likely an indicator of an increase in the concentration of oxygen vacancies due to the need for charge compensation. $\mathrm{Li}$ et al. have also reported a decrease in the lattice constant in $\mathrm{Sr}$ substituted $\mathrm{BiFeO}_{3}$ compounds. ${ }^{23}$

Bond valence sum (BVS) rule gives the information whether the crystal is non-strained perfect or strained. In perfect crystal the formal charge of the cation (anion) is equal to the sum of the bond valences around this cation (anion) according to BVS. This rule is satisfied only if the stress introduced by the coexistence of different structural units can be relieved by the existence of enough degrees of freedom in the crystallographic structure. ${ }^{31}$ The departure from the BVS rule is, therefore, a measure of the existing stress in the bonds of the structure. The bond valences calculated for $\mathrm{Bi}, \mathrm{Sr}$ and $\mathrm{Fe}$ cations from the $\mathrm{Bi} / \mathrm{Sr}-\mathrm{O}$ and $\mathrm{Fe}-\mathrm{O}$ bond distances are enlisted in ESI Table S2. $\dagger$ The BVS sum of Sr cation increases from 2.81 to 3.62 with increasing $\mathrm{Sr}$ content from $5 \%$ to $25 \%$, higher than the expected in this compound. Fe cations exhibit valences of around 2.9 slightly lower than the expected. These results indicate the $\mathrm{Sr}$ cations are over-bonded and $\mathrm{Fe}$ cations are under-bounded in this structure. In other words $\mathrm{Sr}-\mathrm{O}$ bonds are under compressive stress and $\mathrm{Fe}-\mathrm{O}$ 
bonds are under tensile stress giving rise to a structure with a relatively high metastable character.

\subsection{FESEM and TEM analysis}

The morphological analyses of the synthesized samples were done by the field emission scanning electron microscopy (FESEM) technique. FESEM micrographs for $x=0.0,0.15$ and 0.25 samples are shown in Fig. $3(\mathrm{a}-\mathrm{c})$. FESEM images indicate that the synthesized pristine $\mathrm{BiFeO}_{3}$ and $\mathrm{Bi}_{1-x} \mathrm{Sr}_{x} \mathrm{FeO}_{3}(x=0.15$ and 0.25 ) samples have dense morphology of spherical grains with size ranging between 45 and $90 \mathrm{~nm}$. Elemental analysis in these samples was carried out by using the EDS spectra. Typical EDS patterns of pristine $\mathrm{BiFeO}_{3}$ and $\mathrm{Bi}_{1-x} \mathrm{Sr}_{x} \mathrm{FeO}_{3}(x=0.15$ and 0.25 ) samples are shown in Fig. $3(\mathrm{~d}-\mathrm{f})$. The chemical composition of pristine $\mathrm{BiFeO}_{3}$ agrees with the nominal composition: $1: 1: 3$ approximately. Besides the obvious signals for $\mathrm{O}, \mathrm{Bi}$ and Fe, the EDS spectra show a weak signal of Sr for $x=0.15$ and 0.25 samples. The measured quantitative values yield atomic percentages of $\mathrm{Bi}, \mathrm{Sr}$ and $\mathrm{Fe}$ are $18.03 \%, 16.66 \%$ and $1.14 \%$, respectively, for $x=0.15$ sample and $18.20 \%, 15.82 \%$ and $3.35 \%$, respectively, for $x=0.25$ sample. This showed that $\mathrm{Sr}$ ions were effectively incorporated into the host material.

Shape, size, lattice interplaner spacing and crystallinity of the synthesized nanostructured samples were further studied by using HRTEM technique. The TEM images of $\mathrm{Bi}_{1-x} \mathrm{Sr}_{x} \mathrm{FeO}_{3}$ samples with $x=0.0,0.15$ and 0.25 are shown in Fig. $4(\mathrm{a}-\mathrm{c})$, respectively. It is evident that spherical nanoparticles of size around 45-90 $\mathrm{nm}$ are observed for $x=0.0,0.15$ and 0.25 samples. It can be noticed that particle size decreases with increasing $\mathrm{Sr}$ concentration in $\mathrm{BiFeO}_{3}$. The lattice strain due to ionic size mismatch between $\mathrm{Sr}$ and $\mathrm{Bi}$, enhances the rate of nucleation and reduces the particle growth. The selected area electron diffraction (SAED) pattern of $\mathrm{Bi}_{0.85} \mathrm{Sr}_{0.15} \mathrm{FeO}_{3}$ sample is also shown in Fig. 4(d). The diffraction pattern comprising of discrete rings indicates the polycrystalline nature of the sample. The simulated rings pattern for $\mathrm{Bi}_{0.85} \mathrm{Sr}_{0.15} \mathrm{FeO}_{3}$ sample with the intensity of diffraction peaks is also shown in Fig. 4(d). Fig. 4(e) clearly shows the lattice interplaner spacing of $\mathrm{Bi}_{0.85} \mathrm{Sr}_{0.15} \mathrm{FeO}_{3}$ nanoparticles which indicates that fine nanoparticles are well crystallized. The Fast Fourier Transform (FFT) using Gatan

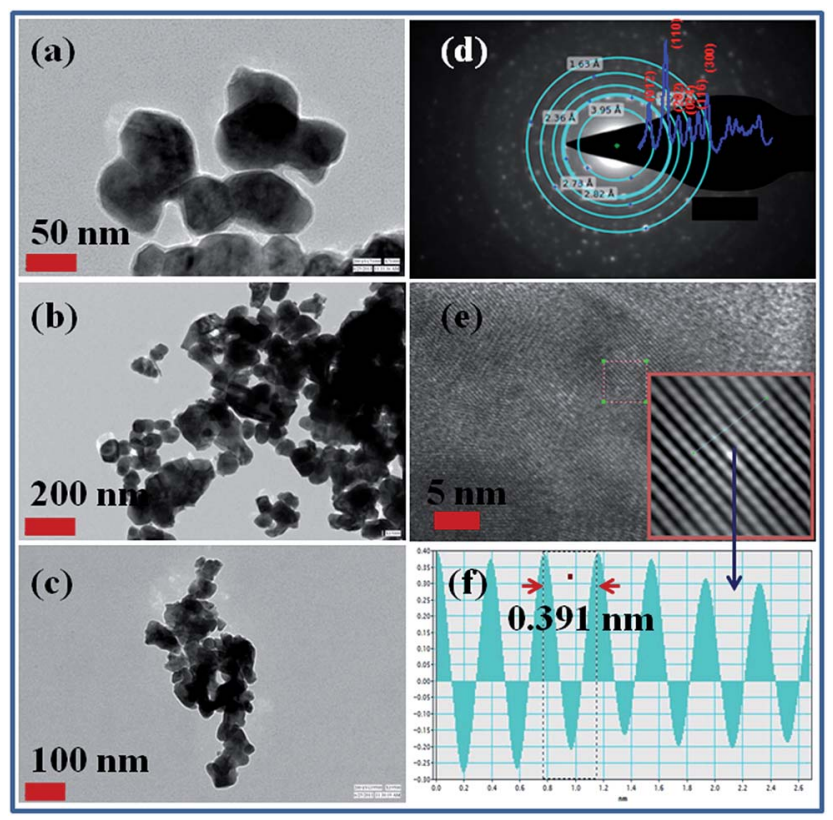

Fig. 4 TEM images of $\mathrm{Bi}_{1-x} \mathrm{Sr}_{x} \mathrm{FeO}_{3}$ nanoparticles (a) $x=0.0$, (b) $x=$ 0.15 , (c) $x=0.25$, (d) selected area diffraction pattern for $x=0.15$ nanoparticles with simulated ring pattern. (e) High resolution TEM image for $x=0.15$ nanoparticles; the inset represents the fast Fourier transform (FFT) of the image, ( $f$ ) the FFT was used to measure the interplanar distance corresponding to (012) plane.

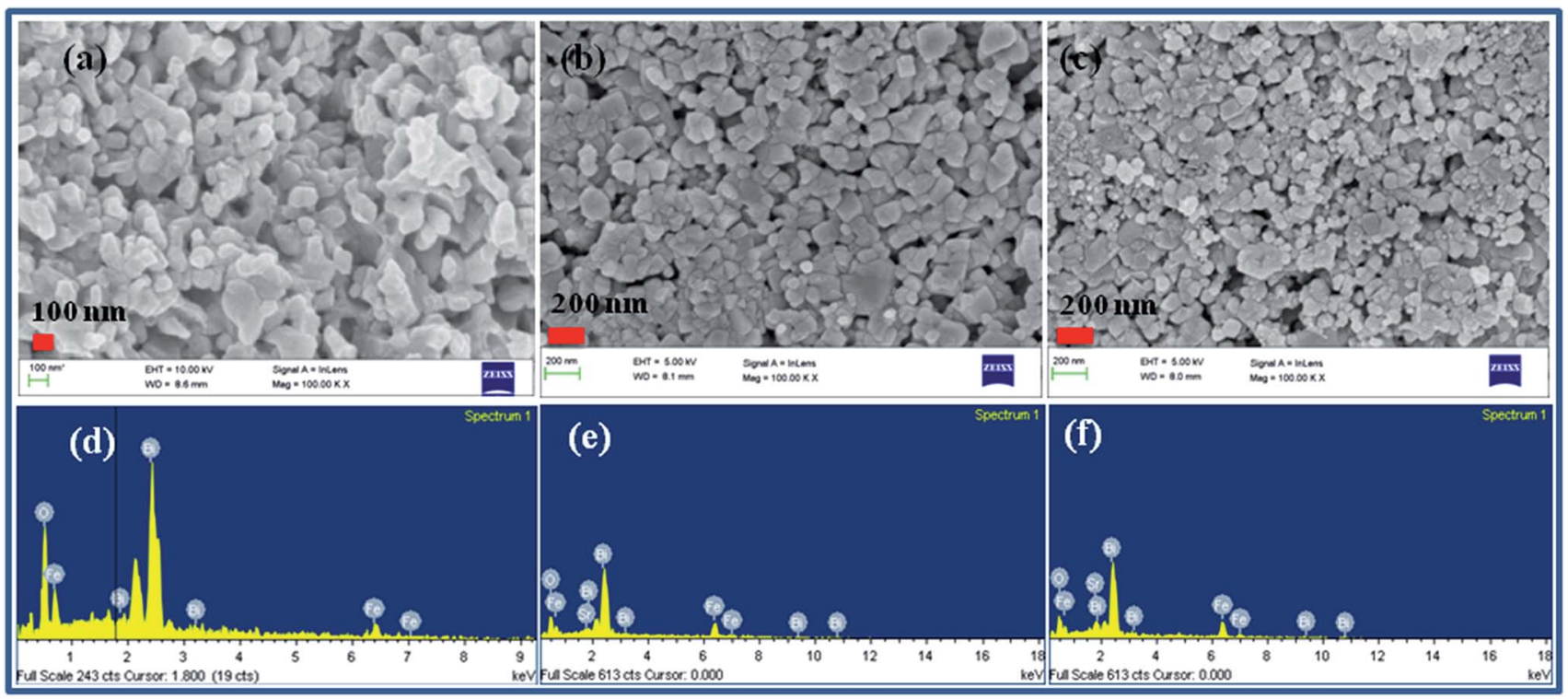

Fig. 3 FESEM micrographs of $\mathrm{Bi}_{1-x} \mathrm{Sr}_{x} \mathrm{FeO}_{3}$ nanoparticles, (a) $x=0.0$, (b) $x=0.15$ and $(\mathrm{c}) x=0.25$. Typical EDS patterns of $\mathrm{Bi}_{1-x} \mathrm{Sr}_{x} \mathrm{FeO}_{3}$ nanoparticles, (d) $x=0.0$, (e) $x=0.15$ and (f) $x=0.25$. 
Microscopy Suite software has been employed to measure the interplaner spacing and the FFT image is shown in the inset of Fig. 4(e). Fig. 4(f) shows the lattice plane intensity profile corresponding to Fig. 4(e), confirming the interplaner spacing of $0.391 \mathrm{~nm}$ corresponding to (012) plane of the $\mathrm{Bi}_{0.85} \mathrm{Sr}_{0.15} \mathrm{FeO}_{3}$ nanoparticles.

\subsection{Raman analysis}

Fig. 5(a) shows the room temperature Raman spectra in the range $50-1500 \mathrm{~cm}^{-1}$ for $\mathrm{Bi}_{1-x} \mathrm{Sr}_{x} \mathrm{FeO}_{3}(x=0-0.25)$ nanoparticles. The assignment of observed Raman modes of distorted rhombohedral perovskite structure of $\mathrm{BiFeO}_{3}$ with space group $R 3 c$ is based on first principal calculations carried out by Hermet et $a .^{32}$ and experimentally reported FTIR data by Chen et $a l .{ }^{33}$ and Raman data by Porporati et al. and Bielecki et al. ${ }^{34,35}$ The fitted Raman spectra for $\mathrm{Bi}_{1-x} \mathrm{Sr}_{x} \mathrm{FeO}_{3}(x=0.0,0.15$ and 0.25 ) nanoparticles are shown in Fig. 5(b)-(d), respectively. The observed modes position and FWHM of $\mathrm{E}$ and A modes for $\mathrm{Bi}_{1-x} \mathrm{Sr}_{x} \mathrm{FeO}_{3}(x=0-0.25)$ nanoparticles are summarized in ESI Table S3. $\dagger$ First Raman active mode near $75 \mathrm{~cm}^{-1}$ splits into two modes $\mathrm{E}\left(\mathrm{TO}_{1}\right)$ and $\mathrm{E}\left(\mathrm{LO}_{1}\right)$. Similarly both $\mathrm{LO}$ and TO modes are present for $\mathrm{E}(8)$ and $\mathrm{E}(9)$. The Raman modes doublet $\mathrm{E}\left(\mathrm{TO}_{1}\right)$, $\mathrm{E}\left(\mathrm{LO}_{1}\right)$ near $75 \mathrm{~cm}^{-1}, \mathrm{E}\left(\mathrm{TO}_{2}\right)$ mode at $139.2 \mathrm{~cm}^{-1}$ and $\mathrm{A}_{1}\left(\mathrm{TO}_{1}\right)$ mode at $172.3 \mathrm{~cm}^{-1}$ are due to the displacement of $\mathrm{Bi}$ atoms due to the activation of lone pair $6 \mathrm{~s}^{2}$ electrons of $\mathrm{Bi}^{3+}$ along the $c$-axis of hexagonal unit cell. The shifting of the first order modes $\mathrm{E}\left(\mathrm{LO}_{1}\right) / \mathrm{E}\left(\mathrm{TO}_{1}\right)$ with increasing the $\mathrm{Sr}$ content in $\mathrm{BiFeO}_{3}$ samples is associated with strain via phonon deformation potentials $\alpha$, $\beta$ and $\gamma$,

$$
\Delta \omega_{\mathrm{E}}=\alpha\left(\varepsilon_{x x}+\varepsilon_{y y}\right)+\beta\left(\varepsilon_{z z}\right)+\gamma\left(\varepsilon_{x x}-\varepsilon_{y y}\right),
$$

where $\varepsilon_{x x}, \varepsilon_{y y}$ are the normal strains in the plane and $\varepsilon_{z z}$ in the $c$ axis direction, respectively. ${ }^{36,37}$ The suppression and shifting of Raman mode $\mathrm{E}\left(\mathrm{TO}_{2}\right)$ related to $\mathrm{Bi}-\mathrm{O}$ bond towards the higher wavenumber with increasing the $\mathrm{Sr}$ content in $\mathrm{BiFeO}_{3}$ is an indication of structural phase transition from rhombohedral to tetragonal. ${ }^{38}$ The other interesting feature of the Raman spectra is the change in the intensity of $\mathrm{A}_{1}\left(\mathrm{TO}_{1}\right)$ mode in comparison with the $\mathrm{E}\left(\mathrm{TO}_{1}\right), \mathrm{E}\left(\mathrm{LO}_{1}\right)$ and $\mathrm{E}\left(\mathrm{TO}_{2}\right)$ with increasing the $\mathrm{Sr}$ content in $\mathrm{BiFeO}_{3}$ samples, which is an evidence for the spin dependent scattering mechanism with the magnetic anisotropy. ${ }^{37}$ In the case of magnetically ordered system, the intensity of the Raman mode can be given by the relation,

$$
I=\left|R+M\left\langle S_{i} S_{j}\right\rangle / S^{2}\right|^{2}
$$

where $R$ is the spin independent part, $M$ is the magnetic moment, $\left\langle S_{i} S_{j}\right\rangle / S^{2}$ is the nearest neighbor spin correlation function. $^{37,39}$ The enhancement of $\mathrm{A}_{1}\left(\mathrm{TO}_{1}\right)$ intensity in comparison with the $\mathrm{E}\left(\mathrm{TO}_{2}\right)$ with increasing the $\mathrm{Sr}$ content in $\mathrm{BiFeO}_{3}$ is due to different to the spin reorientation transitions with increasing the $\mathrm{Sr}$ content in $\mathrm{BiFeO}_{3}$ samples. The next mode with $\mathrm{A}_{1}\left(\mathrm{TO}_{2}\right)$ symmetry at $218.4 \mathrm{~cm}^{-1}$ is soft oxygen mode and is related with the $\mathrm{a}^{-} \mathrm{a}^{-} \mathrm{a}^{-}$oxygen displacement vector. ${ }^{32}$
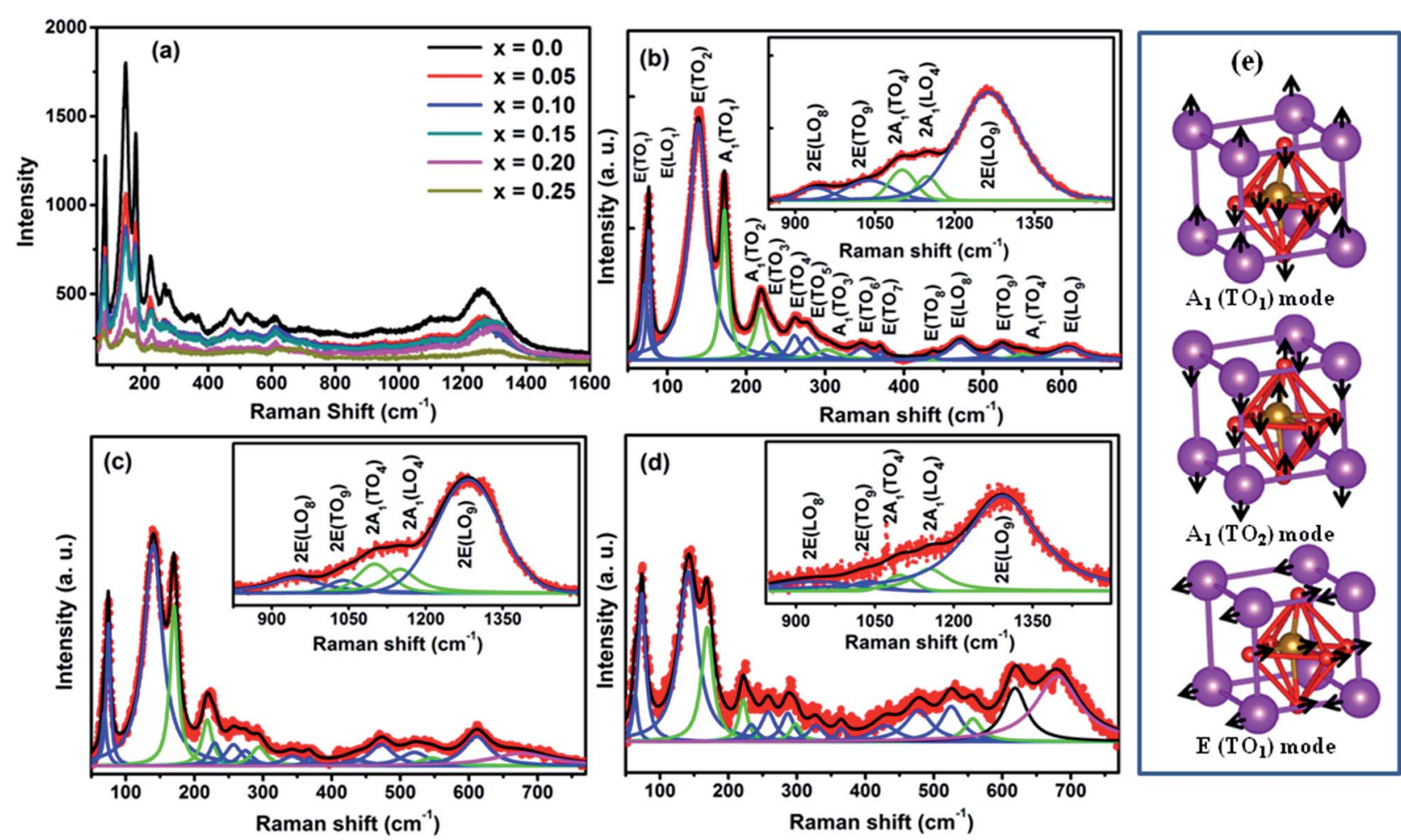

Fig. 5 (a) Raman spectra of $\mathrm{Bi}_{1-x} \mathrm{Sr}_{x} \mathrm{FeO}_{3}$ nanoparticles at room temperature. (b) Deconvoluted first order Raman modes for $x=0.0$. Inset shows the second order modes for $x=0.0$. (c) Deconvoluted first order Raman modes for $x=0.15$. Inset shows the second order modes for $x=0.15$. (d) Deconvoluted first order Raman modes for $x=0.25$. Inset shows the second order modes of for $x=0.25$. (e) Illustrations show the $A_{1}$ and $\mathrm{E}$ vibration normal modes. 
The $\mathrm{A}_{1}\left(\mathrm{TO}_{1}\right)$ and $\mathrm{A}_{1}\left(\mathrm{TO}_{2}\right)$ modes are associated to the structural distortions in comparison with the ideal cubic perovskite structure with space group $P m \overline{3} m$. Fig. 5(e) illustrates the $\mathrm{A}_{1}$ and $\mathrm{E}$ vibration modes. The change in the position and FWHM of the modes with increasing the $\mathrm{Sr}$ content in $\mathrm{BiFeO}_{3}$ indicated the lattice distortion.

The second-order Raman phonon modes of $\mathrm{Bi}_{1-x} \mathrm{Sr}_{x} \mathrm{FeO}_{3}$ $(x=0.0,0.15,0.25)$ nanoparticles are shown in the inset of Fig. 5(b)-(d), respectively. There are five vibrational modes from $900 \mathrm{~cm}^{-1}$ to $1400 \mathrm{~cm}^{-1}$. These second-order modes labeled as $2 \mathrm{E}\left(\mathrm{LO}_{8}\right), 2 \mathrm{E}\left(\mathrm{TO}_{9}\right), 2 \mathrm{~A}_{1}\left(\mathrm{TO}_{4}\right), 2 \mathrm{~A}_{1}\left(\mathrm{LO}_{4}\right)$ and $2 \mathrm{E}\left(\mathrm{LO}_{9}\right)$ are the combination modes and overtones produced by the first-order modes positioned between 450 and $630 \mathrm{~cm}^{-1} \cdot \cdot^{35,40,41}$ These second order phonon modes are assigned to long and short $\mathrm{Fe}-$ $\mathrm{O}$ (defined as Fe-O1 and Fe-O2) bond, respectively, where $\mathrm{O} 1$ are axial and $\mathrm{O} 2$ are equatorial ions. ${ }^{41}$ The $\mathrm{Fe}-\mathrm{O} 2$ is related to the octahedral rotation critical to weak ferromagnetic behavior in $\mathrm{BiFeO}_{3}$. The structural distortion due to $\mathrm{Sr}$ doping should influence Raman modes due to the spin phonon coupling in these samples. The intensity of second order phonon modes of $\mathrm{Sr}$ doped $\mathrm{BiFeO}_{3}$ samples decreases as compared to pure $\mathrm{BiFeO}_{3}$ sample indicating the change in rotation of oxygen octahedral critical to weak ferromagnetism through superexchange interaction. ${ }^{41}$ The variation of intensity of these second overtones predicts that magnetization might enhance with Sr content in $\mathrm{BiFeO}_{3}$, indicating the spin-two phonon coupling in these samples. The second order phonon peaks are associated with the strong spin lattice coupling arising from the interaction between the adjacent magnetic sublattices.

Fig. 6(a-c) shows the Raman scattering spectra of the $\mathrm{Bi}_{1-x} \mathrm{Sr}_{x} \mathrm{FeO}_{3}(x=0.05,0.15$ and 0.25$)$ nanoparticles, using two laser sources with different energy values (2.41 eV and $1.58 \mathrm{eV})$. Using $514.5 \mathrm{~nm}(2.41 \mathrm{eV})$ laser source, which is around $0.2 \mathrm{eV}$ higher than the band gap value, the intensity of the second order phonon modes at $1255 \mathrm{~cm}^{-1}$ is of the same order as that of the corresponding fundamental modes. ${ }^{\mathbf{2 0 , 4 2}}$ The intensity of the second order modes around $1255 \mathrm{~cm}^{-1}$, observed by using the laser source of $785 \mathrm{~nm}(1.58 \mathrm{eV})$. Laser source, is negligible because it does not have enough energy for direct and indirect electronic transitions. Another remarkable finding by using $514.5 \mathrm{~nm}$ and $785 \mathrm{~nm}$ laser sources is a notable intensity variation of the fundamental modes $\sim 218 \mathrm{~cm}^{-1}$. It is important to mention that the intensity variations observed in some vibrational modes are exclusively related to the atoms taking part in the electronic transition in the resonance Raman phenomenon. ${ }^{42}$ In $\mathrm{BiFeO}_{3}$ ceramics, the top of the valence band is composed of strong hybridization among $\mathrm{O} 2 \mathrm{p}$ and $\mathrm{Bi} 6 \mathrm{p}$ and also the bottom of the conduction band comprises of $\mathrm{Fe} 3 \mathrm{~d}$ states. The optical band gap of the $\mathrm{BiFeO}_{3}$ ceramics is due to the hybridization between the Fe $3 \mathrm{~d}$ and $\mathrm{O} 2 \mathrm{p}$ states. ${ }^{43}$ The Raman mode $\sim 218 \mathrm{~cm}^{-1}$ is related to the Fe (3d) atoms. These facts could mean that when the energy of the laser source is sufficient to promote an-electronic transition from the valence band to the lower conduction band in $\mathrm{BiFeO}_{3}$, a perturbation occurs in the electronic density of the $3 \mathrm{~d}$ orbitals of the Fe atoms. ${ }^{42}$ It consequently changes the polarizability of iron atoms resulting in enhancement of the intensity of $218 \mathrm{~cm}^{-1}$ mode. These

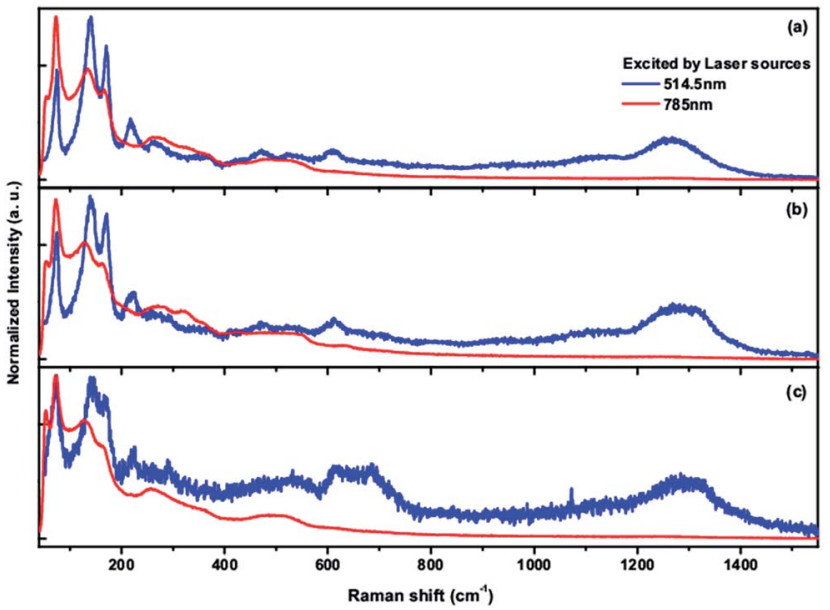

Fig. 6 Raman spectra of $\mathrm{Bi}_{1-x} \mathrm{Sr}_{x} \mathrm{FeO}_{3}$ sample employing two different lasers as excitation source at room temperature, (a) $x=0.05$, (b) $x=$ 0.15 and $(c) x=0.25$

results confirm that electronic transitions take place under excitation with $514.5 \mathrm{~nm}$ laser radiations, allowing the resonance effect.

\subsection{X-ray Photoelectron Spectroscopy (XPS) analysis}

In order to identify the elements, chemical shift, oxidation state of elements and oxygen vacancies of the $\mathrm{Sr}$ doped $\mathrm{BiFeO}_{3}$ samples, detailed XPS analysis has been carried out. The XPS survey spectra of the $\mathrm{Bi}_{1-x} \mathrm{Sr}_{x} \mathrm{FeO}_{3}(x=0.15$ and 0.20$)$ samples are presented in Fig. 7. The XPS survey spectra reveal the presence of $\mathrm{Bi}, \mathrm{Fe}, \mathrm{O}$, and $\mathrm{Sr}$ without any other trace impurities except for a small amount of carbon. This confirms the chemical compositions of the $\mathrm{Sr}$ doped $\mathrm{BiFeO}_{3}$ samples. For narrow scan spectra, the core level $\mathrm{C} 1 \mathrm{~s}(285.0 \mathrm{eV})$ peak is taken as a reference for the calibration of the binding energy values obtained for the elements. The narrow scan XPS spectra of $\mathrm{Bi} 4 \mathrm{f}$, Fe $2 p$, Sr $3 \mathrm{~d}$ and $\mathrm{O} 1 \mathrm{~s}$ lines for $\mathrm{Bi}_{1-x} \mathrm{Sr}_{x} \mathrm{FeO}_{3}(x=0.20$ and 0.25$)$ samples are shown in Fig. 8. Fig. 8(a) shows that Bi 4 f doublet consisting of two peaks at 158.43 and $163.75 \mathrm{eV}$, which are from $\mathrm{Bi}-\mathrm{O}$ bonds. The moderate shifting of $\mathrm{Bi}$ if peaks towards the higher binding energy with increasing $x$ indicates the substitution of $\mathrm{Sr}^{2+}$ ions at $\mathrm{Bi}^{3+}$ sites in $\mathrm{BiFeO}_{3}$ lattice. The chemical shift in $\mathrm{Bi} 4 \mathrm{f}_{7 / 2}$ and $\mathrm{Bi} 4 \mathrm{f}_{5 / 2}$ peaks arises due to variation in electro-negativity of $\mathrm{Bi}, \mathrm{Sr}, \mathrm{Fe}$ and $\mathrm{O}$ elements. The covalency/ ionicity of $\mathrm{Bi}-\mathrm{O}, \mathrm{Sr}-\mathrm{O}$ and $\mathrm{Fe}-\mathrm{O}$ bonds have been calculated for $x=0.15$ and 0.20 samples. The fraction of covalency $\left(F_{\mathrm{c}}\right)$ is estimated from the difference in anion and cation electronegativity values $\left(\Delta E_{\mathrm{N}}\right)$ as: $F_{\mathrm{c}}=\exp \left(-\left(\Delta E_{\mathrm{N}}\right)^{2} / 4\right)$, while the fraction of ionicity is calculated by: $F_{\mathrm{i}}=\left(1-F_{\mathrm{c}}\right) \cdot{ }^{\mathbf{4 4 , 4 5}}$ According to the electronegativity values of $\mathrm{Bi}, \mathrm{Sr}, \mathrm{Fe}$ and $\mathrm{O}$ elements, the $F_{\mathrm{c}}$ and $F_{\mathrm{i}}$ values for $\mathrm{Bi}-\mathrm{O}, \mathrm{Sr}-\mathrm{O}$ and $\mathrm{Fe}-\mathrm{O}$ bonds are calculated. The fraction of ionicity $\left(F_{\mathrm{i}}\right)$ for $\mathrm{Sr}-\mathrm{O}$ bond $(0.79)$ is much larger than that for Bi-O bond (0.40). This indicates that the bonding energy of $(\mathrm{Bi} / \mathrm{Sr}-\mathrm{O})$ bond in the oxygen octahedron would be larger than that of pure $\mathrm{Bi}-\mathrm{O}$ bond which results in slight shifting of $4 \mathrm{f}$ peaks towards the higher binding energy side with 
increasing $\mathrm{Sr}$ content in $\mathrm{BiFeO}_{3}$ samples. Fig. 8(b) shows Fe 2p XPS core spectra of $\mathrm{Bi}_{1-x} \mathrm{Sr}_{x} \mathrm{FeO}_{3}$ samples with $x=0.15$ and 0.20 . The Fe $2 \mathrm{p}$ doublet consists of two wide peaks of Fe $2 \mathrm{p}_{3 / 2} \sim$ $710.13 \mathrm{eV}$ and $\mathrm{Fe} 2 \mathrm{p}_{1 / 2} \sim 723.45 \mathrm{eV}$ for $x=0.15$, which are mainly ascribed to $\mathrm{Fe}-\mathrm{O}$ bonds. Spin-orbit splitting energy is equal to $13.32 \mathrm{eV}$, which is comparable to the theoretical value of $\mathrm{Fe} 2 \mathrm{p}(13.6 \mathrm{eV})$ for $\mathrm{Fe}_{2} \mathrm{O}_{3} \cdot{ }^{\mathbf{4 4 , 4 5}}$ The $\mathrm{Fe} 2 \mathrm{p}_{1 / 2}$ peak for $\mathrm{Fe}^{3+}$ oxidation state is $13.41 \mathrm{eV}$ above the $\mathrm{Fe} 2 \mathrm{p}_{3 / 2}$ peak which appeared around $709.76 \mathrm{eV}$ for $x=0.20$ sample. In general, satellite peak appears at $8 \mathrm{eV}$ above $2 \mathrm{p}_{3 / 2}$ for $\mathrm{Fe}^{3+}$. In both samples, a satellite peak is observed at $\sim 7.5 \mathrm{eV}$ above Fe $2 \mathrm{p}_{3 / 2}$, which confirms the dominant $3+$ oxidation state of Fe. According to the fitting, the compositional ratio of $\mathrm{Fe}^{2+}: \mathrm{Fe}^{3+}$ is calculated as $27.8: 72.2$ and $35.4: 64.6$ for $x=0.15,0.20$ respectively. The $\mathrm{Sr} 3 \mathrm{~d}$ spectra deconvoluted into two wide peaks of $\mathrm{Sr} 3 \mathrm{~d}_{5 / 2} \sim 346.26 \mathrm{eV}, \mathrm{Sr} 3 \mathrm{~d} 3_{/ 2} \sim 349.81 \mathrm{eV}$ and the broad hump (solder) - due to the SrO for $x=0.15,0.20$ are shown in

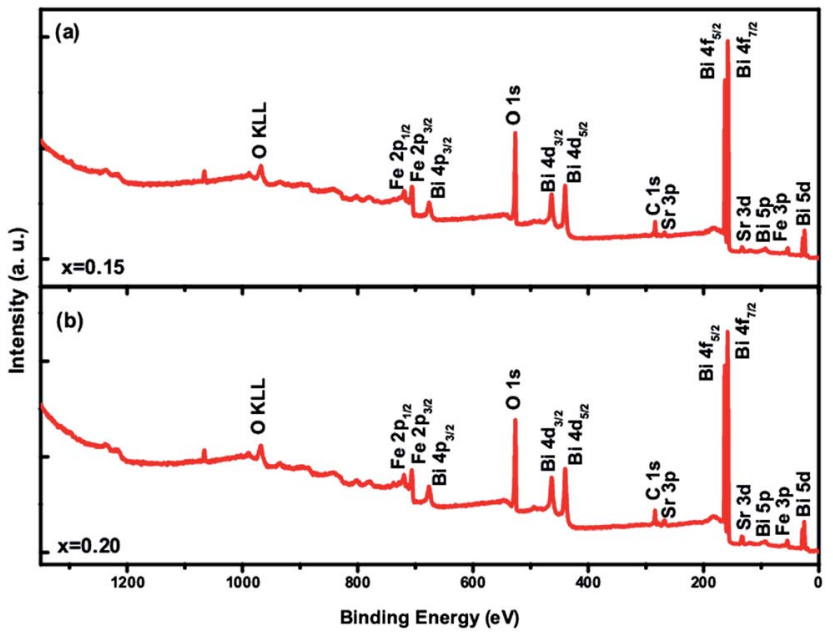

Fig. 7 XPS survey spectra of the of $\mathrm{Bi}_{1-x} \mathrm{Sr}_{x} \mathrm{FeO}_{3}$ samples, (a) $x=0.20$ and (b) $x=0.25$.
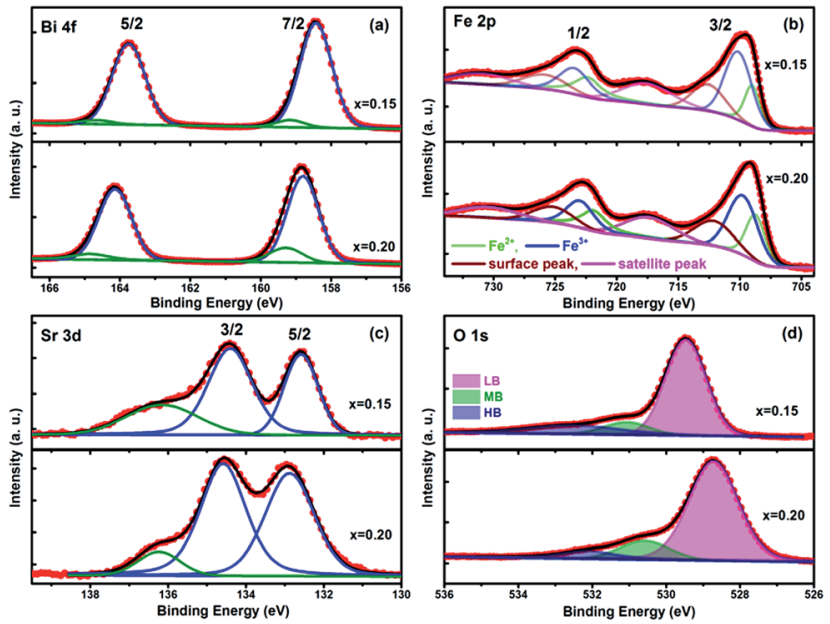

Fig. 8 Deconvoluted core level XPS spectra of (a) Bi 4f, (b) Fe 2p, (c) Sr $3 \mathrm{~d}$ and (d) $\mathrm{O}$ 1s lines $\mathrm{Bi}_{1-x} \mathrm{Sr}_{x} \mathrm{FeO}_{3}$ samples with $x=0.15$ and 0.20 .

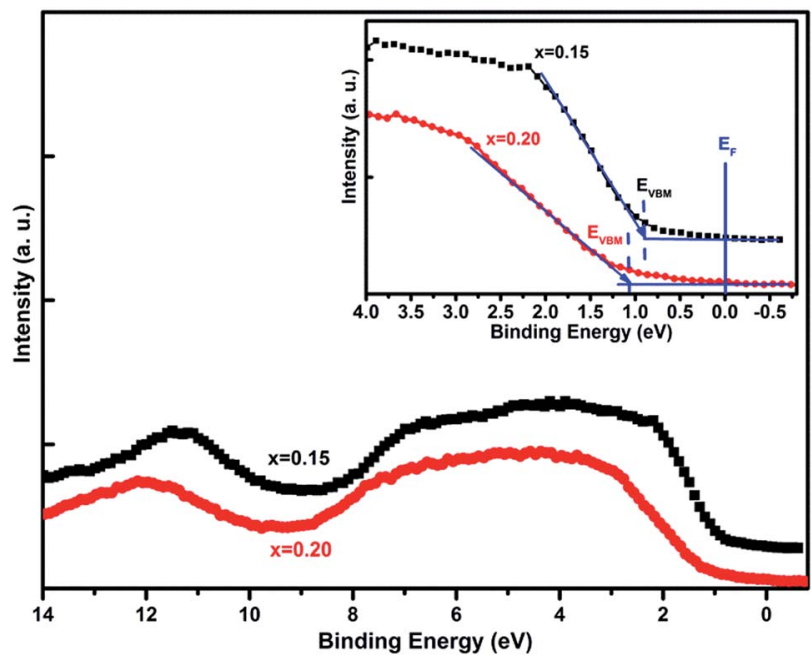

Fig. 9 XPS valence-band spectra of $\mathrm{Bi}_{1-x} \mathrm{Sr}_{x} \mathrm{FeO}_{3}$ samples. Inset shows the magnified view.

Fig. 8(c), which are mainly ascribed to Sr-O bonds. ${ }^{46}$ Fig. $8(d)$ shows the $\mathrm{O} 1 \mathrm{~s}$ peak is de-convoluted into three peaks; the lower binding (LB) energy, medium binding (MB) energy and higher binding (HB) energy for $x=0.15,0.20$ samples. These peaks are attributed to the oxygen present in the lattice, oxygen loss and absorbed oxygen on the surface, respectively. The percentage of the oxygen vacancy concentration is found to be $12.3 \%, 16.2 \%$ for $x=0.15,0.20$, respectively, as calculated by the ratio of $\mathrm{MB} /$ $(\mathrm{LB}+\mathrm{MB}+\mathrm{HB})$. In order to study the evolution of valence band (VB) states in $\mathrm{Bi}_{1-x} \mathrm{Sr}_{x} \mathrm{FeO}_{3}$ samples with $x=0.15$ and 0.20 , we have measured the XPS VB spectra as shown in Fig. 9. A localized peak between 11 and $14 \mathrm{eV}$ binding energy shown in Fig. 9, arises predominantly from $\mathrm{Bi} 6 \mathrm{~s}$ states. The broad peak between 2 and $9 \mathrm{eV}$ binding energy observed in both samples is generally attributed to hybridized Fe $3 \mathrm{~d}-\mathrm{O} 2 \mathrm{p}$ states with a considerable amount of Bi $6 \mathrm{p}$ character. ${ }^{47,48}$ From these data, we have estimated the separation between the valance band maxima $\left(E_{\mathrm{VBM}}\right)$ and the Fermi energy $\left(E_{\mathrm{F}}\right)$ to be $0.90 \mathrm{eV}(x=0.15)$ and $1.03 \mathrm{eV}(x$ $=0.20$ ) for $\mathrm{Bi}_{1-x} \mathrm{Sr}_{x} \mathrm{FeO}_{3}$ samples (inset of Fig. 9). ${ }^{49}$ The position of the valence band maxima $\left(E_{\mathrm{VBM}}\right)$ has been determined from the extrapolation of two linear fits of leading edge and base line. It can be seen that the position of $E_{\mathrm{VBM}}$ is slightly shifted away from the Fermi level with increasing $\mathrm{Sr}$ ion content. Consequently, the XPS results demonstrate that the Sr doping leads to an enhancement of the oxygen vacancy concentration. The increased concentration of oxygen vacancies modulates the energy of the $E_{\mathrm{F}}$ and thus modulates the optical band gap and electrical properties.

\subsection{Vibrating Sample Measurement (VSM) analysis}

Magnetic measurements of prepared samples were recorded to study the effect of Sr doping on magnetic properties of $\mathrm{BiFeO}_{3}$ nanoparticles. The magnetic hysteresis $(\mathrm{M}-\mathrm{H})$ loops for $\mathrm{Bi}_{1-x} \mathrm{Sr}_{x} \mathrm{FeO}_{3}$ samples are shown in Fig. 10(a). The antiferromagnetic (AFM) and weak ferromagnetic (WFM) 
$\mathbf{M}-\mathrm{H}$ curves consists two parts that are paramagnetic (PM) and ferromagnetic (FM). In order to separate out ferromagnetic and paramagnetic contributions in $\mathbf{M}-\mathrm{H}$ hysteresis loops, the $\mathrm{M}-\mathrm{H}$ loops were analyzed by the following equation:

$$
\mathrm{M}(\mathrm{H})=2 \frac{\mathrm{M}_{\mathrm{FM}}^{\mathrm{S}}}{\Pi} \tan ^{-1}\left[\frac{\mathrm{H} \pm \mathrm{H}_{\mathrm{ci}}}{\mathrm{H}_{\mathrm{ci}}} \tan \left\{\frac{\Pi \mathrm{M}_{\mathrm{FM}}^{\mathrm{R}}}{2 \mathrm{M}_{\mathrm{FM}}^{\mathrm{S}}}\right\}\right]+\chi \mathrm{H} .
$$

The first term demonstrates the ferromagnetic part and the second term represents the linear contributions from AFM and/or PM part. ${ }^{42,50}$ The fitted $\mathrm{M}-\mathrm{H}$ curve along with FM and PM parts for $\mathrm{Bi}_{1-x} \mathrm{Sr}_{x} \mathrm{FeO}_{3}: x=0.0,0.15$ and 0.25 samples are shown in Fig. 10(b-d) and the parameters obtained from fitting are listed in Table 1 . The obtained parameters agree with the canted antiferromagnetic order of $\mathrm{BiFeO}_{3}$ ceramics and are comparable with the reported values. ${ }^{51,52}$ Park et al. demonstrated that the weak ferromagnetic response in $\mathrm{BiFeO}_{3}$ can be initiated when the size of the nanoparticles is less than $95 \mathrm{~nm} .{ }^{11,51,52}$ The magnetic response increases rapidly with decreasing the size of the nanoparticles below $62 \mathrm{~nm}$, the period length of spiral spin structure. From the TEM measurements, it was confirmed that size of $\mathrm{Sr}$ doped $\mathrm{BiFeO}_{3}$ nanoparticles varies in the range 45-90 $\mathrm{nm}$, in decreasing order with increasing $\mathrm{Sr}$ content. The antiferromagnetic materials contain two spin sublattices, with ferromagnetic interaction within each sublattice and antiferromagnetic interaction in the inter-sublattices. This two sublattices model
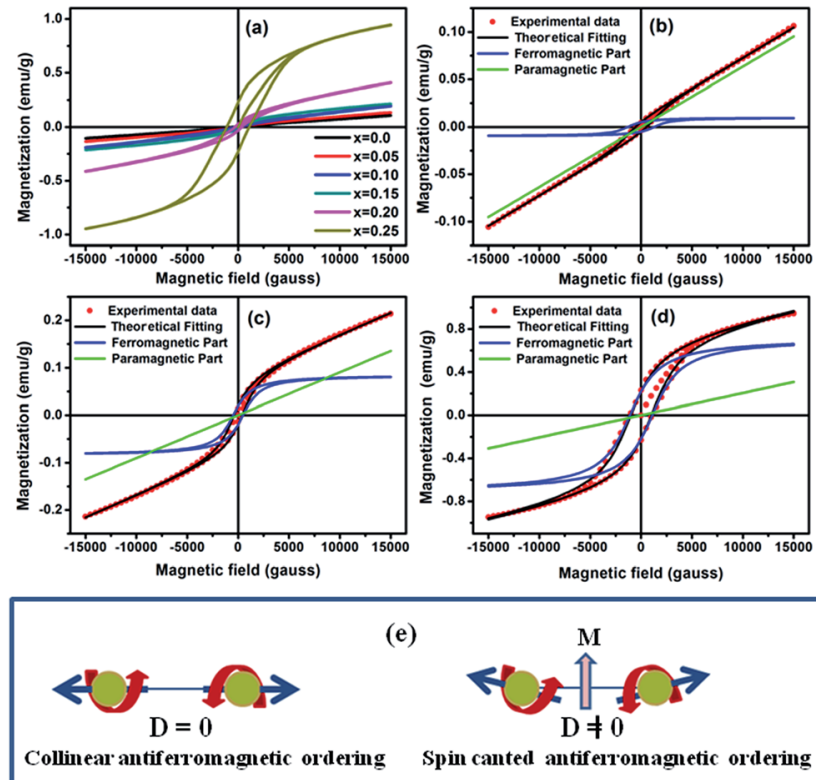

(e)

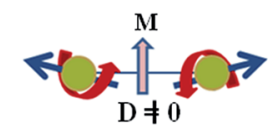

Spin canted antif enromagnetic ordering

Fig. 10 (a) Magnetization versus magnetic field $(\mathrm{M}-\mathrm{H}$ ) curves for $\mathrm{Bi}_{1-x} \mathrm{Sr}_{x} \mathrm{FeO}_{3}$ nanoparticles. Paramagnetic and ferromagnetic fitted magnetization versus magnetic field $(\mathrm{M}-\mathrm{H})$ curve at room temperature for (b) $x=0.0$, (c) $x=0.15$ and (d) $x=0.25$. (e) Canted antiferromagnetic spin structures causing the net magnetic moments in $\mathrm{Sr}$ doped $\mathrm{BiFeO}_{3}$ nanoparticles through Dzyaloshinskii-Moriya (DM) interactions. leads to long-range collinear antiparallel spin structure with zero net magnetic moment due to complete spin compensation between these two sublattices. Moreover, incomplete spin compensation between these two sublattices can also occur in antiferromagnetic materials. ${ }^{\mathbf{1 1}}$ In nano-sized antiferromagnetic materials, long-range antiferromagnetic ordering often gets disturbed at the particle surface. Hence, in antiferromagnetic materials, if resultant small magnetic moment is observed, it could be due to the presence of uncompensated spins in the two sublattices. In addition, the higher surface-tovolume ratio in nanoparticles results in uncompensated spins at the surface and enhanced magnetization (due to disturbed antiferromagnetic ordering). It can be observed from the fitted $\mathrm{MH}$ loops that ferromagnetic ordering contribution increases with increasing Sr content and is maximum for $x=0.25$ sample. The contribution of paramagnetic component increases continuously with increasing $\mathrm{Sr}$ doping. The elementary idea of DM interaction is the induction of magnetization in antiferromagnets due to the modification in 'canted' spins as a result of the ferroelectric distortions. Therefore, it can be suggested that the improved magnetic ordering in $\mathrm{Bi}_{1-x} \mathrm{Sr}_{x} \mathrm{FeO}_{3}$ samples is due to the modifications in its 'canted' spin structure (Fe-O-Fe) which leads to the enhanced magnetic properties as illustrated in Fig. 10(e). With $\mathrm{Sr}$ substitution, structural distortion occurs that results in the canting of spins and therefore the bond angle of $\mathrm{Fe}-\mathrm{O}-\mathrm{Fe}$ changes from $156.8^{\circ}$ to $146.9^{\circ}$, calculated using BondSTR (FULLPROF) shown in Table S2. $\dagger^{\mathbf{4 3 , 5 3}}$ These canted spin antiferromagnetic ordering in $\mathrm{Sr}$ doped $\mathrm{BiFeO}_{3}$ nanoparticles are further explained in EPR studies.

In addition to the antiferromagnetic theory of $\mathrm{BiFeO}_{3}$, we have also quantified the defects and grain boundary effects in $\mathrm{Sr}$ doped $\mathrm{BiFeO}_{3}$ nanoparticles. The specific grain boundary area $\left(S_{\mathrm{GB}}\right)$ defined as the ratio of grain boundary area to volume has been discussed by Tietze et al. ${ }^{54,55}$ For the dense polycrystalline sample with equiaxial grains (no pores and holes), the optimal filling grain shape is a polyhedron with 14 faces called tetrakaidecahedron and the grain boundary area to volume ratio is given as: $S_{\mathrm{GB}}=1.65 / D$, where $D$ is the mean grain size. In case of elongated and flattened grains, $S_{\mathrm{GB}}=$ $1.65 a / D$, where ' $a$ ' is the aspect ratio (ratio of grain width to grain height). The value of ' $a$ ' is less than 1 for elongated grains and greater than 1 for flattened grains. In the case of porous equiaxial polycrystalline sample, the $S_{\mathrm{GB}}$ value decreases approximately by the porosity coefficient $P$ which varies from 0 for non-sintered to 1 for fully compacted polycrystals. ${ }^{5,55}$ The average value of $S_{\mathrm{GB}}$ is $2.3 \times 10^{7} \mathrm{~m}^{2} \mathrm{~m}^{-3}$ for $\mathrm{BiFeO}_{3}$ nanoparticles and $2.5 \times 10^{7} \mathrm{~m}^{2} \mathrm{~m}^{-3}$ for $\mathrm{Bi}_{0.75} \mathrm{Sr}_{0.25^{-}}$ $\mathrm{FeO}_{3}$ nanoparticles corresponding to an average grain size of $70 \mathrm{~nm}$ and $65 \mathrm{~nm}$ respectively. The samples are ferromagnetic only if $S_{\mathrm{GB}}$ exceeds a certain threshold value $S_{\mathrm{TH}}$. The threshold value of $S_{\mathrm{TH}}$ is $1.7 \times 10^{7} \mathrm{~m}^{2} \mathrm{~m}^{-3}$ for pure $\mathrm{BiFeO}_{3}$ ceramics corresponding to average particle size of $95 \mathrm{~nm}$ as calculated from the data reported by Park et al. ${ }^{11,55}$ These results also confirmed the enhanced ferromagnetism in $\mathrm{Sr}$ doped $\mathrm{BiFeO}_{3}$ nanoparticles. 
Table 1 Parameters extracted from fitting the magnetization hysteresis loops of $\mathrm{Bi}_{1-x} \mathrm{Sr}_{x} \mathrm{FeO}_{3}$ nanoparticles

\begin{tabular}{lcccc}
\hline & & \multicolumn{2}{c}{ Ferromagnetic contribution } \\
\cline { 3 - 5 } S. No. & Samples & $\chi \times 10^{-6} \mathrm{emu} \mathrm{g}^{-1}$ gauss $^{-1}$ & $H_{\mathrm{ci}}(\mathrm{Gauss})$ & $M_{\mathrm{FM}}^{\mathrm{s}}\left(\mathrm{emu} \mathrm{g}^{-1}\right)$ \\
\hline 1 & $x=0.00$ & 6.35 & 1300 & 0.0099 \\
2 & $x=0.05$ & 7.4 & 550 & 0.025 \\
3 & $x=0.10$ & 10.15 & 700 & 0.045 \\
4 & $x=0.15$ & 9.02 & 480 & 0.085 \\
5 & $x=0.20$ & 15.6 & 600 & 0.198 \\
6 & $x=0.25$ & 20.5 & 1100 & 0.72 \\
\end{tabular}

\subsection{Electron paramagnet resonance (EPR) analysis}

Fig. 11 shows the room temperature EPR spectra of Sr doped $\mathrm{BiFeO}_{3}$ nanoparticles. The three parameters ( $g$-factor, asymmetry parameter $P_{\text {asy }}$ and signal width $\Delta B_{\mathrm{p}-\mathrm{p}}$ ) calculated from EPR measurement have been correlated with the magnetic structure of the samples. The $g$ values were calculated by using the formula $h \nu=g \mu_{\mathrm{B}} H$, where $\nu$ is operating frequency, $\mu_{\mathrm{B}}$ is Bohr magneton and $h$ is Planck's constant. The asymmetry parameter $P_{\text {asy }}$ is defined as $P_{\text {asy }}=\left(1-h_{\mathrm{U}} / h_{\mathrm{L}}\right)$ where $h_{\mathrm{U}}$ is the height of the absorption peak above the base line and $h_{\mathrm{L}}$ is the height of the absorption peak below the base line of the first derivative of the magnetic resonance absorption signal. $\Delta B_{\mathrm{p}-\mathrm{p}}$ is the width of the signal defined as the separation between the upper peak and the lower peak. ${ }^{55-57}$ The calculated values of $g$, $P_{\text {asy }}$ and $\Delta B_{\mathrm{p}-\mathrm{p}}$ are given in Table 2. Interestingly, the EPR line shifts towards lower magnetic field which gives increasing $g$ values for $x=0.0$ to 0.25 samples. The degree of spin canting may be calculated through vector parameter $D$ which is defined as: $D \approx(\Delta g / g) J_{\text {super }}$, where $\Delta g$ is deviation of $g$ from value 2, $J_{\text {super }}$ is the superexchange interaction coefficient and is assumed to be constant for all the samples. The value $D$ is largest for $x=0.25$ sample as seen from $\Delta g / g$ values in Table 2 . This supports the $\mathbf{M}-\mathrm{H}$ loop measurement results that the ferromagnetic interactions are continuously increasing with
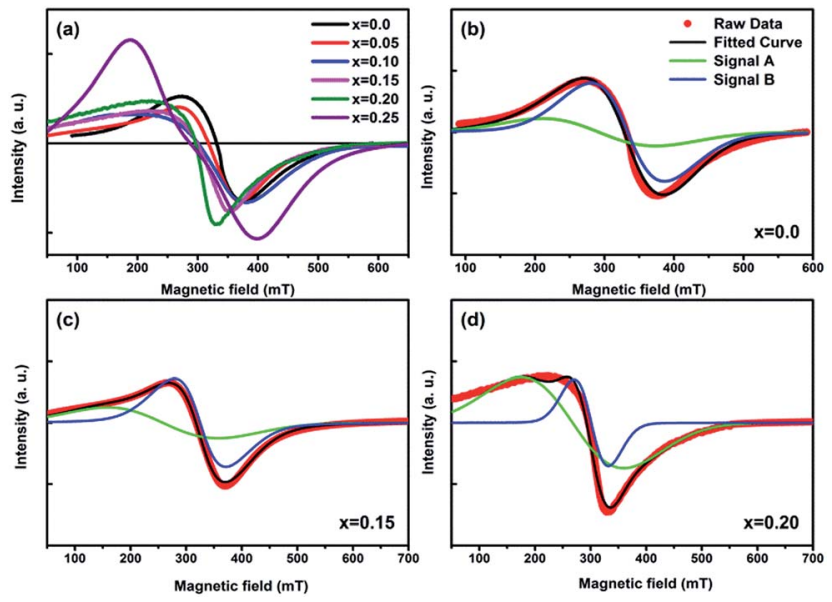

Fig. 11 Electron paramagnetic resonance (EPR) spectra of $\mathrm{Bi}_{1-x} \mathrm{Sr}_{x}-$ $\mathrm{FeO}_{3}$ nanoparticles at room temperature. Fitted ESR spectra of (b) $x=$ 0.0 , (c) $x=0.15$ and (d) $x=0.20$. increasing $\mathrm{Sr}$ content in $\mathrm{BiFeO}_{3}$. The high asymmetry in the EPR spectra suggested that the EPR signal is composed of two peaks. For the sake of convenience, the broad and narrow signals are designated as signal $\mathrm{A}$ and signal $\mathrm{B}$, respectively as shown in Fig. $11(\mathrm{~b}-\mathrm{d})$ for $x=0.0,0.15$ and 0.20 samples. The broad and weak Gaussian signal A $\left[H_{\mathrm{pp}}=2236\right.$ Gauss (peak-to-peak line width) and $g$-value as 2.19] and the intense and narrow Gaussian signal B $\left[H_{\mathrm{pp}}=1194\right.$ Gauss and $g$-value as 2.04] were fitted for $x=0.0,0.15$ and 0.20 samples as shown in Fig. 11(bd). The signal A is related to the ferromagnetic part and the signal B is related to the paramagnetic part. ${ }^{58}$ The area under signal A increases continuously with increasing Sr concentration which indicates that ferromagnetic contribution increases with increasing Sr concentration in these samples.

\subsection{Mössbauer spectroscopy}

The electronic and magnetic properties of $\mathrm{Bi}_{1-x} \mathrm{Sr}_{x} \mathrm{FeO}_{3}$ samples with $x=0.0,0.10,0.15$ and 0.25 were also systematically investigated by Mössbauer spectroscopy. The Mössbauer spectrum provides valuable information about the electronic density at the nuclei (through isomer shift, IS), the possible electric field gradient (quadrupole splitting, QS) and the magnetic environment (magnetic hyperfine splitting, HF). Mössbauer spectra fitted with one doublet and one sextet for pure $\mathrm{BiFeO}_{3}$ nanoparticles and fitted with one sextet for $x=0.10,0.15$ and 0.25 are shown in Fig. 12(a)-(d) respectively. The Mössbauer spectrum for pure $\mathrm{BiFeO}_{3}$ sample is a superposition of quadrupolar doublet and magnetic sextet as shown in Fig. 12(a). This collapsed quadrupolar (doublet and sextet) spectrum is related to the particle size distribution within the synthesized sample. The tiny doublet in Mössbauer spectrum may be related to

Table 2 Calculated ESR parameters of $\mathrm{Bi}_{1-x} \mathrm{Sr}_{x} \mathrm{FeO}_{3}$ nanoparticles at room temperature

\begin{tabular}{lllllr}
\hline S. No. & Sample & $g$ & $\Delta g / g$ & $\Delta B_{\mathrm{p}-\mathrm{p}}$ (Gauss) & $P_{\text {asy }}$ \\
\hline 1 & $x=0.0$ & 2.05 & 0.028 & 1098 & 0.22 \\
2 & $x=0.05$ & 2.12 & 0.06 & 1014 & 0.37 \\
3 & $x=0.10$ & 2.24 & 0.12 & 1725 & 0.51 \\
4 & $x=0.15$ & 2.25 & 0.125 & 1284 & 0.53 \\
5 & $x=0.20$ & 2.27 & 0.135 & 1077 & 0.47 \\
6 & $x=0.25$ & 2.35 & 0.175 & 2090 & -0.09
\end{tabular}



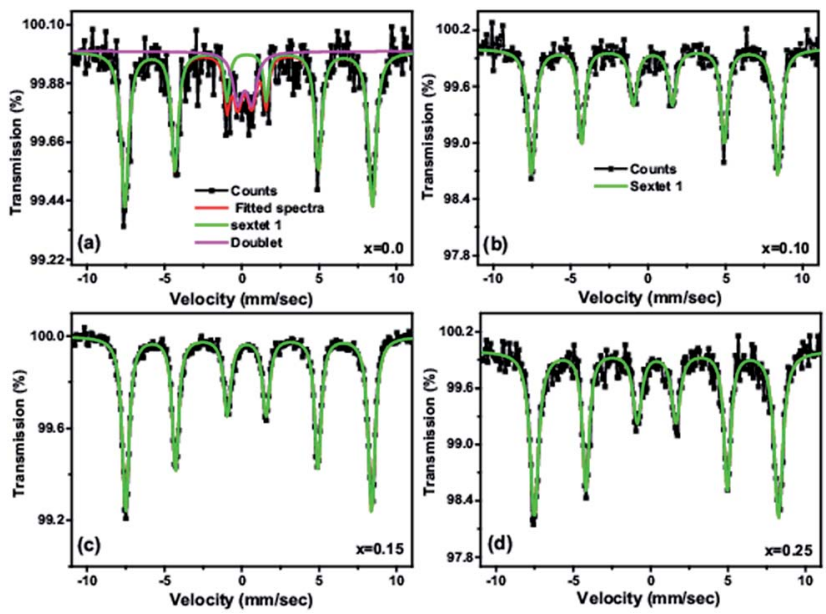

Fig. 12 Room temperature Mössbauer spectra for (a) $x=0$, (b) $x=$ 0.10 , (c) $x=0.15$ and (d) $x=0.25$ samples fitted with one sextet.

superparamagnetic relaxation of smaller particles. Park et al. has reported similar type of Mössbauer spectra for $\mathrm{BiFeO}_{3}$ nanoparticles of size less than $95 \mathrm{~nm} .{ }^{11}$ One sextet fitting hyperfine parameters are tabulated in Table 3 . The isomer shift (IS) which is a measure of the oxidation state of Fe atoms is found to be $\sim 0.37 \mathrm{~mm} \mathrm{~s}^{-1}$ for all the samples. The reported values of IS varies in the range $0.6-1.7 \mathrm{~mm} \mathrm{~s}^{-1}$ for $\mathrm{Fe}^{2+} ; 0.05-0.5$ $\mathrm{mm} \mathrm{s}^{-1}$ for $\mathrm{Fe}^{3+}$ and -0.15 to 0.05 for $\mathrm{Fe}^{4+} .{ }^{59}$ This indicates that $\mathrm{Fe}^{3+}$ oxidation state is dominant in present samples. The observed values of QS are $0.1275,0.1147,0.1065$ and -0.015 $\mathrm{mm} \mathrm{s}^{-1}$ for $x=0.0,0.10,0.15$ and 0.25 samples respectively. The decrease of QS with sign change on increasing Sr concentration in $\mathrm{BiFeO}_{3}$ nanoparticles has been observed. This can be explained by distortion (compression) of oxygen octahedron and/or displacement of Fe ions across diagonal of pseudo-cubic crystal cell in the doped samples. Similar results have also been reported by Xiao et al. ${ }^{60}$ Hyperfine magnetic field (HF) decreases from 49.70 to 49.05 Tesla with increasing Sr content for $x=0.0$, $0.10,0.15$ and 0.25 samples. It is known that $\mathrm{Fe}^{3+}$ ions do not possess any orbital moment and as a consequence there is no orbital magnetism. Therefore, hyperfine magnetic field is only caused by contact Fermi interaction which is proportional to the difference of electronic densities belonging to spin-up and spindown states. The difference appears due to polarization of the $3 \mathrm{~d}$ electronic shell caused by interaction of Fe ion with neighbor oxygen ions. The Rietveld analysis showed that the $\mathrm{Sr}^{2+}$

Table 3 Hyperfine parameters obtained from one-sextet fitting of the Mössbauer spectra: IS-Isomer Shift, QS-electric Quadrupole Splitting, $\mathrm{HF}$-hyperfine magnetic field of $\mathrm{Bi}_{1-x} \mathrm{Sr}_{x} \mathrm{FeO}_{3}$ nanoparticles

\begin{tabular}{llllll}
\hline Sample & Type & HF (Tesla) & QS $\left(\mathrm{mm} \mathrm{s}^{-1}\right)$ & IS $\left(\mathrm{mm} \mathrm{s}^{-1}\right)$ & Area ratio \\
\hline$x=0.0$ & Sextet 1 & 49.70 & 0.1275 & 0.377 & $82.01 \%$ \\
& Doublet & & 0.9069 & 0.1918 & $17.99 \%$ \\
$x=0.10$ & Sextet 1 & 49.475 & 0.1147 & 0.3694 & $100 \%$ \\
$x=0.15$ & Sextet 1 & 49.302 & 0.1065 & 0.3725 & $100 \%$ \\
$x=0.25$ & Sextet 1 & 49.05 & -0.015 & 0.3767 & $100 \%$
\end{tabular}

substitution at $\mathrm{Bi}^{3+}$ site leads decrease in lattice parameters and creation of oxygen vacancies. Hence, the distortion in the crystal structure with increasing $\mathrm{Sr}^{2+}$ content results in the change of Fe ion surroundings which gives rise to the hyperfine magnetic structure. Lebeugle et al. reported that the spin cycloid causes the broadening of Mössbauer spectra lines. ${ }^{61}$ The line broadening (FWHM: Full Width at Half Maximum) of the sextet decreases with increasing $\mathrm{Sr}$ content indicating the destruction of the spin cycloid in these samples. ${ }^{60}$ The larger FWHM and asymmetry of intensity of the lines suggested the existence of at least two nonequivalent positions of Fe ions and therefore two sextets fitting were also done as shown in Fig. 13. The twosextets fitting matches reasonably well with experimental data points and the obtained hyperfine parameters are shown in Table 4. A comparison of the obtained values of the parameters of hyperfine interactions with available data in the literature for iron ions with different oxygen co-ordinations indicates that two sextets with approximately equal shift of the line (IS $\approx 0.33-$ 0.39 ) and small QS correspond to $\mathrm{Fe}^{3+}$ ions in a weakly distorted octahedral oxygen environment ( $\mathrm{Fe}-\mathrm{O})$. The quadrupole splitting and hyperfine magnetic fields of the two sextets approach to each other with increasing $\mathrm{Sr}$ concentration in $\mathrm{BiFeO}_{3}$
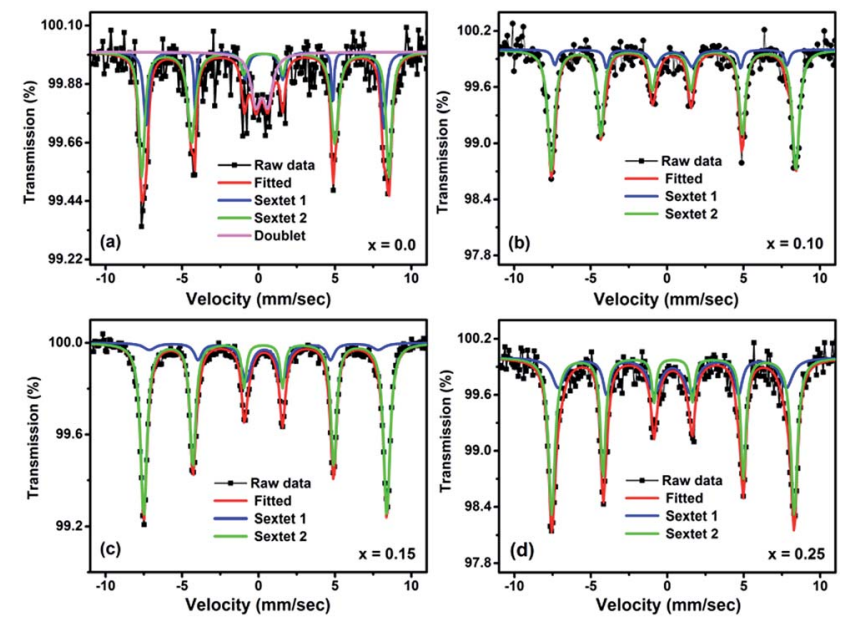

Fig. 13 Mössbauer spectra for (a) $x=0.0$, (b) $x=0.10$, (c) $x=0.15$ and (d) $x=0.25$ samples fitted with two sextets.

Table 4 Hyperfine parameters obtained from two-sextet fitting of the Mössbauer spectra: IS-Isomer Shift, QS-electric Quadrupole Splitting, $\mathrm{HF}$-hyperfine magnetic field of $\mathrm{Bi}_{1-x} \mathrm{Sr}_{x} \mathrm{FeO}_{3}$ nanoparticles

\begin{tabular}{llllll}
\hline Sample & Type & HF (Tesla) & QS $\left(\mathrm{mm} \mathrm{s}^{-1}\right)$ & IS $\left(\mathrm{mm} \mathrm{s}^{-1}\right)$ & Area ratio \\
\hline \multirow{2}{*}{$x=0.0$} & Sextet 1 & 48.3006 & 0.0718 & 0.3856 & $25.44 \%$ \\
& Sextet 2 & 50.2383 & 0.1456 & 0.3779 & $56.87 \%$ \\
& Doublet & & 0.7886 & 0.2149 & $17.69 \%$ \\
$x=0.10$ & Sextet 1 & 47.1481 & -0.175 & 0.3422 & $16.25 \%$ \\
& Sextet 2 & 49.6674 & 0.1281 & 0.3636 & $83.75 \%$ \\
$x=0.15$ & Sextet 1 & 46.5065 & -0.0278 & 0.3626 & $21.81 \%$ \\
& Sextet 2 & 49.4138 & 0.1275 & 0.3761 & $78.19 \%$ \\
$x=0.25$ & Sextet 1 & 46.3206 & -0.0164 & 0.3381 & $36.48 \%$ \\
& Sextet 2 & 49.2635 & -0.0153 & 0.3797 & $63.52 \%$
\end{tabular}


samples and this indicates the appearance of equivalence of $\mathrm{Fe}$ ions.

\section{Conclusions}

In summary, $\mathrm{Bi}_{1-x} \mathrm{Sr}_{x} \mathrm{FeO}_{3}$ nanoparticles were successfully synthesized by the sol-gel route. X-ray diffraction, TEM, Raman, XPS, VSM, EPR and Mössbauer spectroscopy were applied to investigate the structure-dependent evolution of properties of perovskite $\mathrm{Bi}_{1-x} \mathrm{Sr}_{x} \mathrm{FeO}_{3}$ nanoparticles. Rietveld refinement of XRD patterns suggested the coexistence of rhombohedral and pseudo tetragonal phases in $25 \% \mathrm{Sr}$ doped $\mathrm{BiFeO}_{3}$ sample. The TEM images demonstrated that particle size lies in nano range and decreases with increasing $\mathrm{Sr}$ concentration in $\mathrm{BiFeO}_{3}$. Significant changes in intensity, position and width of $\mathrm{E}\left(\mathrm{LO}_{1}\right)$, $\mathrm{E}\left(\mathrm{TO}_{2}\right), \mathrm{E}\left(\mathrm{LO}_{9}\right)$ Raman modes have been observed with increasing Sr content confirming the structural distortion. XPS spectra indicated the dominancy of $\mathrm{Fe}^{3+}$ oxidation state and slight increase in oxygen vacancies with increasing Sr content in $\mathrm{BiFeO}_{3}$ samples. The ferromagnetic ordering component increases with increasing $\mathrm{Sr}$ content in $\mathrm{BiFeO}_{3}$ samples due to the distorted spin structure and uncompensated surface spins which is further confirmed from EPR studies. Local magnetic behavior investigated by ${ }^{57} \mathrm{Fe}$ Mössbauer spectroscopy ruled out any valence fluctuations of $\mathrm{Fe}$ with $\mathrm{Sr}$ substitution and the hyperfine field corroborates the magnetization data. One sextet fitting of Mössbauer spectra showed changes in QS hyperfine parameter and line-width with increasing $\mathrm{Sr}$ content in $\mathrm{BiFeO}_{3}$ nanoparticles suggesting the destruction of spin cycloid. The analysis of the spectral asymmetry demonstrated the line broadening mechanism and two sextets fitting provided further evidence for spin cycloid destruction.

\section{Acknowledgements}

Authors are thankful to Department of Science and Technology (DST) (Grant number SR/FTP/PS-91/2009) to carry out this research work. The authors are thankful to SAIF AIIMS, New Delhi and SAIF IIT, Chennai for TEM, VSM and EPR measurements. The authors are also thankful to INUP program IISc, Bangalore for Raman and FESEM measurements.

\section{Notes and references}

1 M. Fiebig, T. Lottermoser, D. Fröhlich, A. V. Goltsev and R. V. Pisarev, Nature, 2002, 419, 818; M. Fiebig, J. Phys. D: Appl. Phys., 2005, 38, R123.

2 W. Eerenstein, N. D. Mathur and J. F. Scott, Nature, 2006, 442, 759.

3 G. Catalan and J. F. Scott, Physics and applications of bismuth ferrite, Adv. Mater., 2009, 21, 2463-2485.

4 L. W. Martin, Dalton Trans., 2010, 39, 10813; L. W. Martin, S. P. Crane, Y.-H. Chu, M. B. Holcomb, M. Gajek, M. Huijben, C.-H. Yang, N. Balke and R. Ramesh, J. Phys.: Condens. Matter, 2008, 20, 434220.

5 Y. Li, M.-S. Cao, D.-W. Wang and J. Yuan, $R S C A d v .$, 2015, 5, 77184.
6 B. Sun, Y. Liu, W. Zhao and P. Chen, RSC Adv., 2015, 5, 13513. 7 S. Das, S. Rana, S. M. Mursalin, P. Rana and A. Sen, Sens. Actuators, B, 2015, 218, 122.

8 D. Tiwari, D. J. Fermin, T. K. Chaudhuri and A. Ray, J. Phys. Chem. C, 2015, 119, 5872; S. Acharya, S. Martha, P. C. Sahoo and K. Parida, Inorg. Chem. Front., 2015, 2, 807.

9 A. Rogov, M. Irondelle, F. Ramos-Gomez, J. Bode, D. Staedler, S. Passemard, S. Courvoisier, Y. Yamamoto, F. Waharte, D. Ciepielewski, P. Rideau, S. Gerber-Lemaire, F. Alves, J. Salamero, L. Bonacina and J.-P. Wolf, ACS Photonics, 2015, 2(10), 1416.

10 M. Escobar Castillo, V. V. Shvartsman, D. Gobeljic, Y. Gao, J. Landers, H. Wende and D. C. Lupascu, Nanotechnology, 2013, 24, 355701.

11 T. J. Park, G. C. Papaefthymiou, A. J. Viescas, A. R. Moodenbaugh and S. S. Wong, Nano Lett., 2007, 7, 766.

12 C.-H. Yang, D. Kan, I. Takeuchi, V. Nagarajan and J. Seidel, Phys. Chem. Chem. Phys., 2012, 14, 15953.

13 B. Bhushan, A. Basumallick, S. K. Bandopadhyay, N. Y. Vasanthacharya and D. Das, J. Phys. D: Appl. Phys., 2009, 42(6), 065004.

14 P. K. Jha, P. A. Jha, P. Kumar, K. Asokan and R. K. Dwivedi, J. Alloys Compd., 2016, 667, 178; Z. X. Cheng, X. L. Wang, Y. Du and S. X. Dou, J. Phys. D: Appl. Phys., 2010, 43, 242001.

15 D. C. Arnold, IEEE Trans. Ultrason. Eng., 2015, 62, 62, DOI: 10.1109/tuffc.2014.006668.

16 J. Zhao, S. Liu, W. Zhang, Z. Liu and Z. Liu, J. Nanopart. Res., 2013, 15, 1969, DOI: 10.1007/s11051-013-1969-7; T. Karthik, T. Durga Rao, A. Srinivas and S. Asthana, J. Mater. Sci.: Mater. Electron., 2015, 26, 8676.

17 W. W. Mao, X. F. Wang, Y. M. Han, X. A. Li, Y. T. Li, Y. F. Wang, Y. W. Ma, X. M. Feng, T. Yang, J. Yang and W. Huang, J. Alloys Compd., 2014, 584, 520; W. W. Mao, X. F. Wang, L. Chu, Y. Y. Zhu, Q. Wang, J. Zhang, J. Yang, X. A. Li and W. Huang, Phys. Chem. Chem. Phys., 2016, 18, 6399.

18 B. Wang, S. Wang, L. Gong and Z. Zhou, Ceram. Int., 2012, 38, 6643.

19 S. Hussain, S. K. Hasanain, G. H. Jaffari, N. Z. Ali, M. Siddique and S. I. Shah, J. Alloys Compd., 2015, 622, 8; T. Hussain, S. A. Siddiqi, S. Atiq and M. S. Awan, Prog. Nat. Sci., 2013, 23, 487.

20 B. Bhushan, A. Basumallick, N. Y. Vasanthacharya, S. Kumar and D. Das, Solid State Sci., 2010, 12, 1063.

21 B. Kundys, A. Maignan, C. Martin, N. Nguyen and C. Simon, Appl. Phys. Lett., 2008, 92, 112905.

22 K. Balamurugan, N. H. Kumar and P. N. Santhosh, J. Appl. Phys., 2009, 105, 07D909.

23 J. Li, Y. Duan, H. He and D. Song, J. Alloys Compd., 2001, 315, 259.

24 S. K. Mandal, T. Rakshit, S. K. Ray, S. K. Mishra, P. S. R. Krishna and A. Chandra, J. Phys.: Condens. Matter, 2013, 25, 055303.

25 X. Wang, S. Y. Wang, W. F. Liu, F. Guo, X. J. Xi, H. J. Wang and D. J. Li, Mod. Phys. Lett. B, 2014, 28(7), 1450050.

26 S. Gosh, S. Das Gupta, A. Sen and H. S. Maiti, J. Am. Ceram. Soc., 2005, 88(5), 1349-1352; M. Arora, P. C. Sati, S. Chauhan, 
S. Chhoker, A. K. Panwar and M. Kumar, J. Supercond. Novel Magn., 2013, 26, 443.

27 H. D. Megaw and C. N. W. Darlington, Acta Crystallogr., Sect. A: Cryst. Phys., Diffr., Theor. Gen. Crystallogr., 1975, 31, 161.

28 S. M. Selbach, T. Tybell, M. A. Einarsrud and T. Grande, Chem. Mater., 2007, 19, 6478.

29 J. Rodriguez-Carvajal, FullProf: A Rietveld Refinement and Pattern Matching Analysis Program (Version: April 2008), Laboratoire Léon Brillouin (CEA-CNRS), France, 2000.

30 S. Diodati, L. Nodari, M. M. Natile, U. Russo, E. Tondello, L. Lutterotti and S. Gross, Dalton Trans., 2012, 41, 5517.

31 J. A. Alonso, M. J. Martínez-Lope, J. L. García-Muñoz and M. T. Fernández-Díaz, J. Phys.: Condens. Matter, 1997, 9, 6417.

32 P. Hermet, M. Goffinet, J. Kreisel and P. Ghosez, Phys. Rev. B: Condens. Matter Mater. Phys., 2007, 75, 220102.

33 P. Chen, X. Xu, C. Koenigsmann, A. C. Santulli, S. S. Wong and J. L. Musfeldt, Nano Lett., 2010, 10, 4526.

34 A. A. Porporati, K. Tsuji, M. Valant, A. K. Axelsson and G. Pezzotti, J. Raman Spectrosc., 2010, 41, 84.

35 J. Bielecki, P. Svedlindh, D. T. Tibebu, S. Cai, S.-G. Eriksson, L. Börjesson and C. S. Knee, Phys. Rev. B: Condens. Matter Mater. Phys., 2012, 86, 184422.

36 M. Cazayous, D. Malka, D. Lebeugle and D. Colson, Appl. Phys. Lett., 2007, 91, 071910.

37 J.-P. Zhou, R.-J. Xiao, Y.-X. Zhang, Z. Shi and G.-Q. Zhu, J. Mater. Chem. C, 2015, 3, 6924.

38 D. Varshney and A. Kumar, J. Mol. Struct., 2013, 1038, 242.

39 N. Suzuki and H. Kamimura, J. Phys. Soc. Jpn., 1973, 35, 985. 40 J. Hlinka, J. Pokorny, S. Karimi and I. M. Reaney, Phys. Rev. B: Condens. Matter Mater. Phys., 2011, 83, 020101.

41 M. O. Ramirez, M. Krishnamurthi, S. Denev, A. Kumar, S. Y. Yang, Y. H. Chu, E. Saiz, J. Seidel, A. P. Pyatakov, A. Bush, D. Viehland, J. Orenstein, R. Ramesh and V. Gopalan, Appl. Phys. Lett., 2008, 92, 022511.

42 P. Kumar, N. Shankhwar, A. Srinivasan and M. Kar, J. Appl. Phys., 2015, 117, 194103.

43 M. Sakar, S. Balakumar, P. Saravanan and S. Bharathkumar, Nanoscale, 2015, 7, 10667.

44 Z. Quan, W. Liu, H. Hu, S. Xu, B. Sebo, G. Fang, M. Li and X. Zhao, J. Appl. Phys., 2008, 104, 084106.
45 A. Tamilselvan, S. Balakumar, M. Sakar, C. Nayek, P. Murugavel and K. S. Kumar, Dalton Trans., 2014, 43, 5731. 46 Q.-H. Wu, M. Lin and W. Jaegermann, Mater. Lett., 2005, 59, 1980-1983.

47 D. Mazumdar, R. Knut, F. Thöle, M. Gorgoi, S. Faleev, O. N. Mryasov, V. Shelke, C. Ederer, N. A. Spaldin, A. Gupta and O. Karis, J. Electron Spectrosc. Relat. Phenom., 2016, 208, 63.

48 P. Kumar, P. Pal, A. K. Shukla, J. J. Pulikkotil and A. Dogra, Phys. Rev. B: Condens. Matter Mater. Phys., 2015, 91, 115127.

49 H. Zhang, W. Liu, P. Wu, M. Guo, X. Xu, X. Xi, J. Gao, G. Rao and S. Wang, J. Mater. Chem. C, 2015, 3, 4141.

50 L. R. Shah, H. Zhu, W. G. Wang, B. Ali, T. Zhu, X. Fan, Y. Q. Song, Q. Y. Wen, H. W. Zhang, S. I. Shah and J. Q. Xiao, J. Phys. D: Appl. Phys., 2010, 43, 035002.

51 F. Huang, Z. Wang, X. Lu, J. Zhang, K. Min, W. Lin, R. Ti, T. T. Xu, J. He, C. Yue and J. Zhu, Sci. Rep., 2013, 3, 2907. 52 S.-Z. Lu and X. Qi, J. Am. Ceram. Soc., 2014, 97(7), 2185.

53 H. Feng, J. Magn. Magn. Mater., 2010, 322, 1765.

54 T. Tietze, et al., Sci. Rep., 2015, 5, 8871.

55 S. Chauhan, M. Kumar, S. Chhoker and S. C. Katyal, J. Alloys Compd., 2016, 666, 454.

56 D. Maurya, H. Thota, A. Garg, B. Pandey, P. Chand and H. C. Verma, J. Phys.: Condens. Matter, 2009, 21, 026007.

57 M. Arora, P. C. Sati, S. Chauhan, M. Kumar and S. Chhoker, Mater. Lett., 2014, 132, 327; S. Chauhan, M. Kumar, S. Chhoker, S. C. Katyal and M. Singh, RSC Adv., 2016, 6, 43080 .

58 D. Karmakar, S. K. Mandal, R. M. Kadam, P. L. Paulose, A. K. Rajarajan, T. K. Nath, A. K. Das, I. Dasgupta and G. P. Das, Phys. Rev. B: Condens. Matter Mater. Phys., 2007, 75, 144404.

59 N. N. Greenwood and T. C. Gibb, Mössbauer Spectroscopy, Chapman and Hall London, 1971.

60 R. Xiao, V. O. Pelenovich and D. Fu, Appl. Phys. Lett., 2013, 103, 012901.

61 D. Lebeugle, D. Colson, A. Forget, M. Viret, P. Bonville, J. F. Marucco and S. Fusil, Phys. Rev. B: Condens. Matter Mater. Phys., 2007, 76, 024116. 